Chapter 14

\title{
Stentless Bioprostheses for Aortic Valve Replacement in Calcific Aortic Stenosis
}

\author{
Kaan Kirali \\ Additional information is available at the end of the chapter \\ http://dx.doi.org/10.5772/55373
}

\section{Introduction}

The classic case of aortic stenosis is a healthy middle-aged patient with/without symptoms, but in practical life, patients with severe calcific aortic valve come with several and severe comorbidities such as advanced age, coronary artery disease, atherosclerotic aorta, significant left ventricular dysfunction. Aortic valve replacement (AVR) is the only options in these patients, and it requires patient-by-patient analysis of clinical, echocardiograhic, and hemodynamic data with associated pathologies. The curative treatment of calcific aortic valve stenosis is the replacement of the aortic valve with a prosthetic valve, and selection of a perfect prosthetic valve is the main goal to get a successful treatment. But, there is no any perfect heart valve prosthesis which may mimic the characteristics of the normal native aortic valve: excellent hemodynamics, life-long durability, thromboresistance, and excellent implantability. That means that native valve disease will be traded for prosthetic valve disease and the outcome of AVR is affected by the type of prosthetic valve. Mechanical valves are non-limited durable, but have a substantial risk of hematologic complications (thromboemboli, thrombotic obstruction, hemorrhage related life-long anticoagulation therapy) with/without hemolysis potential. In contract, bioprosthetic valves have a low risk of thromboembolism without anticoagulation, but their durability is limited by calcific or noncalcific tissue deterioration. Biological prostheses, especially homografts, are often believed to be the substitute of choice in AVR, but the limited availability of homografts prevents their more broadly usage. To overcome this problem and all possible complications of mechanical valves, xenogenic biological prostheses have been developed. The design of bioprosthetic valves purports to mimic the anatomy of the native aortic valve and their flow characteristics are better than mechanical valves, whereas stentless bioprostheses have hemodynamic performance similar to the healthy native aortic valve. Although stented bioprostheses can be implanted easier, 
they decrease the effective orifice area due to the rigid stent and result turbulent flow through the valve. Stented valves also increase stress at the attachment of the stent which cause earlier primary tissue failure. Stentless biologic valves have been introduced into clinical practice to solve all these problems and to reproduce the anatomy and function of the native aortic valve, but their clinical use has still not exceeded the number of stented aortic bioprostheses because of more demanding technique of implantation. To gain more widespread clinical use and general recommendation of stentless bioprostheses, their advantages and simple implantation techniques must be popularized.

It is believed that the aortic root is probably the best stent for the native or prosthetic aortic valve. The anatomy and function of the aortic root may dampen the mechanical stress to which the leaflets are subjected during diastole. The ideal stentless prosthesis should have no synthetic materials, preserve the aortic root dynamics, restore flexibility and distensibility of the native valve annulus after decalcification, and have minimal xenograft aortic wall, short implantation time, and excellent hemodynamic performance to facilitate the recovery of left ventricular function.

\subsection{Historical background}

Homografts were the first biological prostheses used in clinical practice to treat aortic valve stenosis in early 1960s, and they were the first stentless valves, too [1,2]. The authors used the aortic root of the patient to secure the homograft aortic valve in the subcoronary position. The most complicated implantation technique and the restricted availability of homografts prevented their widespread usage. First stentless pig and calf xenografts were used in limited patients, but the valves were abandoned because of poor tissue fixation [3]. Stented bioprostheses were considered as the gold standard for several years, but abnormal stress on the leaflets was believed to decrease durability. To overcome this problem with a rigid stent on the aortic position, stentless bioprostheses were re-introduced in the middle of 80's [4], whereas new designed stentless xenografts were proposed and popularized in daily use at the beginning of 1990s [5]. The main problem (early failure of bioprostheses) was solved with new bioengineering improvement (antimineralization, zero-pressure fixation) [6]. The other problem was partial dehiscence when the heterograft contained muscular bar resulting paravalvular leakage in the area corresponding to the muscular bar, and this problem was abolished with a fine Dacron cloth covered the outside wall of the stentless porcine aortic valve along its inflow [7]. Recognizing the range of aortic root variability and disease of the root itself, the concept of stentless valve replacement was expanded to replacement of the entire aortic root. Full root replacement with a bioprosthesis brought the challenges of homeostasis and coronary reimplantation. In spite of hemodynamic advantages proven for the root replacement technique, acceptance was slowed by risk/benefit ratio concerns. The whole aortic root could be prepared and implanted with modified root inclusion or subcoronary implant techniques.

Biological stentless valve can be prepared by pulmonary autograft, homograft, xenograft, autologous or xenogenic pericardium. Pulmonary autograft has limited durability beyond the first decade [8]. The same problem has been observed with homografts in the aortic position, 
especially in younger patients, which are less durable than commercially available stentless bioprostheses and cannot be recommended as the ideal device [9]. The use of the patients own pericardium for constructing a heart valve prosthesis is biologically more appealing than the use of animal tissue or heterologous material. The feasibility of autologous pericardial stentless aortic valve was shown in an animal study [10]. The feasibility and durability of truly stentless autologous pericardial AVR sutured directly onto the aortic wall has been also performed in human recently [11]. Stentless porcine or pericardial xenogenic bioprostheses have been introduced to get better long-term durability and become a routine device when a stentless biologic valve is implanted.

There are a lot of stentless bioprostheses with/without the aortic root in the market, but some of them are not used widespread and implantation of a few xenografts is stopped (Table 1). The first modern (first generation) stentless valves were glutaraldehyde-fixed porcine prostheses with a fully scalloped shape or a complete aortic root (Figure 1). The most preferred approach was root replacement technique because subcoronary approach needed more suture line. The second generation of stentless valves improved the technical difficulties related to free-hand implantation with two rows of sutures for subcoronary implantation of porcine bioprostheses (Figure 2). The third generation of stentless prostheses are made by xenogenic pericardium, because the pericardial valve is free from the compromises of the porcine aortic root, it is flexible, and easy to implant either with an interrupted or running suture technique (Figure 3). There are different xenogenic pericardial valves (bovine or equine), and horse pericardium is thinner, however, stronger than the bovine pericardium and also much more pliable. The fourth generation of stentless valves are produced by a proprietary process and the unique conditioning technology paves the way for autologous repopularization of the valve in patients. The durability of current bioprosthetic heart valves is diminished by glutaraldehyde-associated leaflet calcification or by the host immune reaction. As a novel tissue engineering approach to improving replacement heart valve durability, a new acellular (nonglutaraldehyde-fixed) tissue heart valve for autologous recellularization is developed to limit xenograft antigenicity. As no glutaraldehyde is used in the whole process lack of calcification and also lack of toxicity, and the method delivers a very pliable valve with very low gradients. To use of autologous pericardium fixed with glutaraldehyde avoids any immune reaction between the host and the implanted heart valve and so minimizes tissue calcification and pannus formation. The last generation of stentless valves provides avoidance of suture lines during AVR: closed [transcatheter (transfemoral or transapical)] or open $($ transaortic $=$ sutureless $)$ techniques $($ Figure 4$)$.

\section{Hemodynamic recovery}

Every effort should be made to avoid moderate prosthesis-patient mismatch during AVR. Stentless valves enable to select the largest bioprosthesis to the patient's annulus and provide better aortic root and valve behavior, larger effective orifice area (EOA), reduced transprosthetic gradient and greater left ventricular mass regression. 
(A)
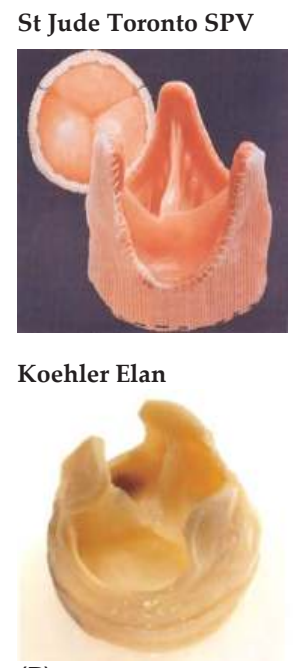

(B)

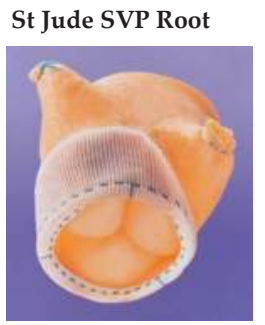

Medtronic Freestyle

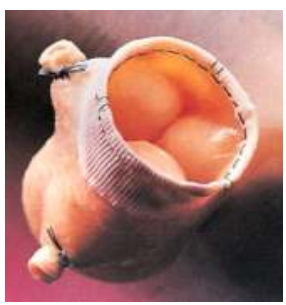

St Jude Medical-Biocor

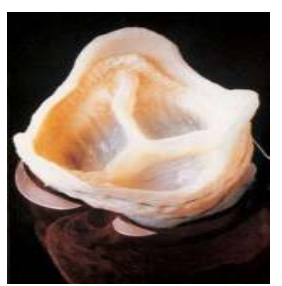

Labcor

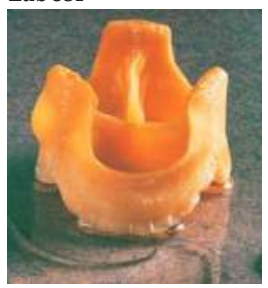

CryoLife-O'Brien

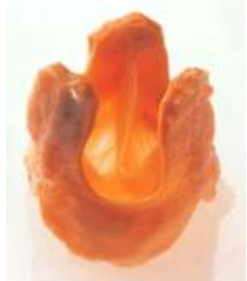

Edwards Prima Plus

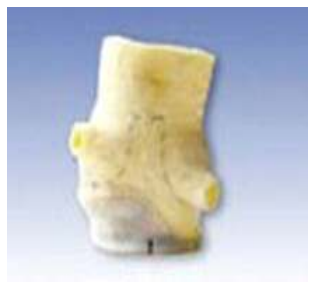

Koehler Elan Root

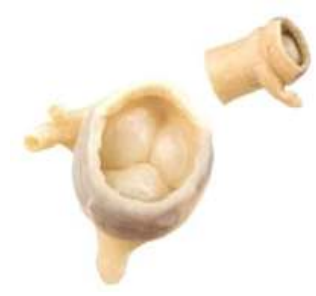

Figure 1. First generation bioprostheses (Porcine Stentless Xenografts) A) Scalloped stentless porcine bioprostheses B) Root stentless porcine bioprostheses.

To prevent early or late prosthetic failure, maintenance of the aortic root with physiological anatomy must be the primary goal during AVR with a stentless prosthesis. Any kind of bioprosthetic valve will deviate from native aortic valve in terms of leaflet dynamics. Stiffening of the aortic root either by glutaraldehyde or by stent degenerates the opening (wrinkles and blurry edges of leaflets) and closing (asynchronism) behavior of native aortic valve leaflets. 


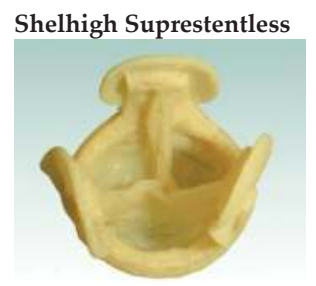

Figure 2. Second generation bioprostheses.

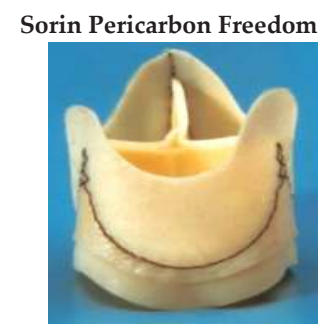

Sorin Pericarbon Freedom SOLO

3F Therapeutics
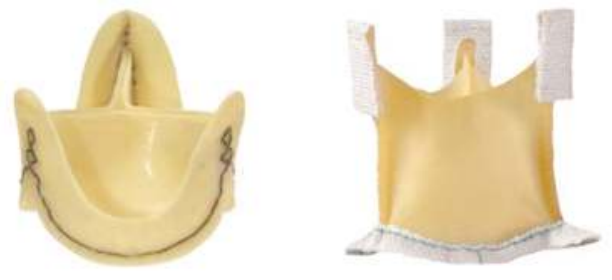

Figure 3. Third generation bioprostheses (Pericardial Stentless Xenografts)
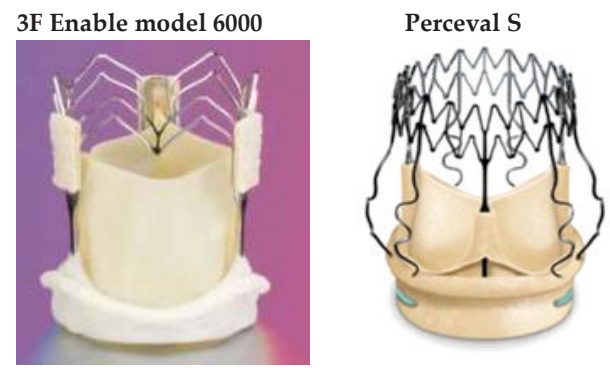

Figure 4. Sutureless Pericardial Stentless Xenografts

Stented valves fixe the native commissures and do not allow cyclic change of the commissural dimension as it normally occurs. This cyclic expansion of the commissural area serves reduction of stress on the leaflets, which is preserved by stentless bioprostheses. Second, the intrinsically obstructive nature of the stented bioprostheses increases pressure gradient and creates turbulent flow patterns, however, normal laminar flow patterns can be restored after AVR with stentless tissue valves. The opening and closing of the stentless biologic valve constitute a passive mechanism responding to pressure difference between the left ventricle and the aorta. Like the native aortic valve, a stress created by this difference heads toward the central coaptation area of the bioprosthesis during diastole. The negative pressure difference during diastole helps prosthetic valve to be closed. The valve opens rapidly at the beginning of ejection because of rising of pressure difference and persists to remain open as a tunnel 


\section{A. Autograft \\ B. Homograft \\ C. Xenografts}

I. First generation (Stentless Porcine Bioprosthesis)

\begin{tabular}{ll}
\hline Dacron reinforced inflow tract & \\
\hline Toronto SPV (stentless porcine valve) & St Jude Medical, Inc., St Paul, MN, USA \\
\hline St Jude Medical-Biocor & St Jude, Belo Horizonte, MG, Brazil \\
\hline CryoLife-O'Brien Model 3000 & CryoLife International Inc, Atlanta, GA, USA \\
\hline Toronto SPV Root & St Jude Medical, Inc., St Paul, MN, USA \\
\hline Edwards Prima Plus & Edwards Lifesciences, Inc., Irvine, CA,USA \\
\hline Medtronic Freestyle & Medtronic, Inc., Minneapolis, MN, USA \\
\hline pericardial reinforced inflow tract & Koehler, Bellshill, Scotland \\
\hline Koehler Elan & \\
\hline Koehler Elan Root & \\
\hline tri-composite design (three noncoronary leaflets) & Labcor, Inc., Belo Horizonte, MG, Brazil \\
\hline Labcor & \\
\hline
\end{tabular}

II. Second generation (porcine with single suture line, No-react treatment)

Shelhigh Suprestentless Shelhigh, Inc, Millburn, NJ, USA

III. Third generation (Stentless Pericardial Bioprosthesis)

porcine pericardium

Sorin Pericarbon Freedom Sorin Biomedica Cardio SpA, Saluggia, Italy

Sorin Pericarbon Freedom SOLO

horse (equine) pericardium

3F Therapeutics

3F Therapeutics, Inc., Lake Forest, CA, USA

IV. Fourth generation (non-gluteraldayhde fixed +

decellularized)

Matrix A

\section{Sutureless generation (Sutureless + Stentless}

\section{Pericardial Bioprosthesis)}

3F Enable model 6000

3F Therapeutics, Inc., Lake Forest, CA, USA

Perceval S

Sorin Biomedica Cardio SpA, Saluggia, Italy

\section{Autologous pericardium}

Table 1. Stentless Bioprostheses. 
during systole, and the aortic root may also expanse at the late diastole to help opening of the leaflets (in native aortic valve, expansion of the aortic root is about $12 \%$ and that starts opening the leaflets to about 20\%). At the end of systole, the backward blood flow into the sinuses of Valsalva (behind prosthetic leaflets) and initialization of pressure difference help prosthetic leaflets to revert to their original closed position. An in-vivo-study has showed that there is no difference in opening velocities among native, stented and subcoronary stentless valves in a porcine model [12]. However, the closing velocities are significantly higher in the pericardial valves. The bending deformation increases when implanting a glutaraldehyde-treated valve subcoronary. Porcine stentless valves display a distinct folding pattern during opening resulting in an altered stress distribution and also tend to fold during opening causing increased leaflet bending stress [13].

One of the key parameters for stentless xenograft performance is the EOA. In spite of the EOA is significantly higher in stentless bioprostheses it is also dependent on the design and the implantation technique of the prostheses. The EOA will increase especially during the first year and the transvalvular gradient drops dramatically in the first 3 to 6 months after surgery, but some further drop may be seen more later [14]. The reason may be remodeling of the left ventricular outflow tract, diminished aortic root edema, and slight dilatation of the aortic root. Transvalvular gradient is closely related to the EOA: the larger orifice area the lower is the transvalvular gradient. The second reason to increase transvalvular gradient is usage of a rigid stent. Avoidance of a stent enlarges inner diameter of prosthetic valve and eliminates intraluminal obstruction which increases the EOA. Several studies have shown transvalvular gradient across stentless valves is always lower than for their stented valves, especially mean and/or peek gradients [15-1617]. The third possible reason can be excessive tissue of a bioprosthesis: the lesser tissue implanted within the recipient aortic root the lesser obstruction. The full root prostheses reduce the intraluminar obstruction because nothing is implanted inside, and they have larger EOA than subcoronary prostheses. The main differences of stentless biologic tissue valves are the specific gravity of the leaflets which is not equal to that of blood like native human aortic leaflets and the specific thickness of the leaflets which is thinner in pericardial tissue valves. Both parameters cause transvalvular gradient during ejection which is lesser in fully pericardial stentless valves than porcine. The other reasons may be small aortic annulus and physically active patients. The change in gradients during exercise is interesting: when cardiac output increases it also increases the transvalvular flow and raises transprosthetic gradient, but these gradients under exercise are lower with stentless valves than stented bioprostheses, which provide better opening-closing behavior [18].

Left ventricular output is maintained by the development of the left ventricular hypertrophy which results in a large pressure gradient across the stenotic valve. The left ventricle mass increases and becomes less compliant. Left ventricular hypertrophy and increased mass can be correlated with sudden death, congestive heart failure, and other cardiovascular events. Left ventricular hypertrophy will regress after AVR regardless of the type of prostheses, and an improved hemodynamic performance of prostheses should result in a faster regression, especially in patients with severe calcific aortic stenosis and left ventricular hypertrophy, because incomplete regression after AVR is related to poor long-term outcome [19]. This 
regression is related to EOA and transvalvular gradient constituted by the prosthetic valve. A significant improvement will occur in all type of valves in the first year, but this improvement is greater and faster with the stentless bioprostheses [20]. A lasting benefit beyond the first year is possible, especially in severely enlarged ventricles [21]. These improvements include mass regression, wall thickening, fractional shortening, and diastolic relaxation. Patients with small aortic annuli or with compromised left ventricular function $(\mathrm{EF}<50 \%)$ might benefit more from stentless prostheses [22,23].

\section{Structural and nonstructural durability}

One of the foremost concern of any tissue valve is its long-term patency, because the limited durability represents the main disadvantage of these devices. Tissue valve degeneration causing stenosis or regurgitation is the primer indication for reoperation.

Durability of any kind of stentless bioprosthesis can be affected adversely by internal (structural) or external (nonstructural) factors.

Structural valve deterioration (SVD) is a primary tissue failure after biological valve implantation. A major cause of SVD is cusp tear with consequent aortic regurgitation where urgent or emergent reoperation is necessary due to congestive heart failure and hemolytic anemia. The other major reason is prosthetic valve sclerosis and calcification which could permit an elective reoperation in stable condition. An in vivo animal study has shown that native aortic valves are significantly more distensible at the level of the sinotubular junction, commissures and ascending aorta when compared with all-valve prosthesis [24]. There is no any study to evaluate how the late scar with/without calcification tissue formation spread and effect this distensibility. We can argue that annular calcification developed during follow-up acts similar in native and stentless valves and fixes the aortic annulus. The zero-pressure fixation and antimineralization techniques have improved durability of tissue valves. To avoid from well known limited durability of xenogenic bioprostheses owing to structural degeneration and calcification, the use of autologous pericardium may be an attractive alternative with several advantages: no immune reaction, minimum tissue calcification and pannus formation, excellent hemodynamics and dynamics of the aortic root, no complicated reoperation [11].

Nonstructural valve deterioration (NSVD) is independent on the xenograft's tissue. In spite of leaflets of xenografts work very well, stentless bioprosthesis shows incompetence. There are several reasons causing prosthetic stenosis or regurgitation (Table 2).

Technical inadequacy during stentless valve implantation cause hemodynamic problems like regurgitation, turbulent flow, uncoaptation or stretching of leaflets which aggregate tissue degeneration. Any increase in mechanical stress causing by surgical implantation techniques has a negative impact on durability. Description of all implantation techniques with their tips is not adequate to avoid iatrogenic valve degeneration, all details of these techniques should be well known. The best way to avoid mechanical stress may be to use the full root replacement technique, but most surgeon do not like to replace the aortic root without any pathology 


\begin{tabular}{l}
\hline A. Endocarditis \\
\hline B. Technically implantation errors \\
\hline C. Aortic root enlargement \\
\hline II. Sinus of Valsalva aneurysm ( \pm rupture) \\
\hline III. Aortic dissection \\
\hline IV. Left ventricular dilatation \\
\hline D. Partial dehiscence after preserved non-coronary sinus \\
\hline E. Insufficiently decalcification \\
\hline I. Poor decalcification (intra-operatively) \\
II. Suture rupture or loosening (post-operatively) \\
\hline III. Calcification on the native aorta (follow-up) \\
F. Subvalvular fibrous band \\
G. Hematologic problems (hemolysis, thrombocytopenia)
\end{tabular}

Table 2. Non-structural Deterioration (regurgitation or stenosis).

(dilatation, calcification) because of higher operative risk. Subcoronary implantation technique is more acceptable approach for isolated AVR with stentless bioprostheses. Technical errors relating to xenograft sizing and failure to achieve appropriate geometry of the xenograft within the aortic root are 2 major reasons for early valve failure. The learning curve associated with subcoronary implantation is the main reason for these technical errors. Suboptimal implantation resulting in distortion of the valve or bulking of valve tissue into the outflow tract may be involved in the evolution of higher gradients. Undersizing of xenograft results regurgitation due to handicapping leaflet coaptation, whereas oversizing may cause higher transvalvular gradient due to making leaflet opening difficult. The other error is to decide and apply the wrong implantation technique, especially in small or dilated aortic root, and subcoronary technique might be associated with higher gradient or regurgitation [25].

On the other hand, improvement of the long term patency of an aortic prosthetic valve is dependent on avoidance of paravalvular complications which can be very serious and cause reoperation. Paravalvular regurgitation is a dangerous long-term result of insufficient decalcification, which causes incompetence suturing or suture rupture during follow-up.

Partial dehiscence of the stentless xenograft indeed occurs and that it has a strong predilection for the preserved non-coronary sinus after modified subcoronary technique. Supposedly, proteolytic enzymes from captured blood cells in the dead space between native and donor aortas or the potential usefulness of biologic glues might prevent adequate fusion of the walls and healing of the anastomosis [26]. 
Subvalvular fibrous band is a rare complication resulting significant left ventricular outflow tract obstruction, which can be a derivative of the pannus discovered on the sewing ring of stented valves. The etiology is unknown, but it may result from thrombus formation or inflammation related to host factors. A chronic inflammatory infiltrate composed of lymphocytes and macrophages occurs in equine or porcine stentless valves, which suggests equal immunogenicity among different various biologic graft materials [27].

\subsection{Aortic valve surgery}

\subsubsection{Cardiopulmonary bypass}

Aortic valve surgery can be performed through a median full sternotomy or upper ministernotomy with conventional or minimal skin incision. The distal ascending aorta cannulation is usually the standard approach in most patients, but the arcus aorta or axiller artery can be also cannulated when the ascending aorta should be replaced [28]. A single dual-stage venous cannula is inserted through the right atrium appendage. After cardiopulmonary bypass is initiated the aorta is clamped and cardiac arrest is be achieved with antegrade isothermic blood cardioplegia administered into the aortic root. Myocardial protection is continued due to retrograde cardioplegic cannula during whole procedure, and retrograde cardioplegia is continuously infused whenever clear visulation of the aortic root is not required [29]. Rarely the retrograde cannula cannot be introduced safely into the coronary sinus, in this situation intermittent antegrade isothermic blood cardioplegia is performed using selective coronary ostial cannulation after transverse aortotomy incision. If both approaches are unsuccessful, bicaval cannulation is performed and the retrograde cannula is placed in the coronary sinus under direct vision. A vent cannula is inserted into the left atrium through the right upper pulmonary vein after cross clamp to prevent the left ventricle distention. Mild-moderate hypothermia $\left(30-32^{\circ} \mathrm{C}\right)$ is achieved and continued during extracorporeal circulation, and rewarming of patients is started before the closure of the aortotomy.

\subsubsection{Aortotomy}

A small transverse aortotomy incision is made initially at least 15 to $20 \mathrm{~mm}$ above the origin of the right coronary ostium or the sinotubular junction. The calcific aortic valve and whole aortic root should be investigated under direct vision and decided which approach will be preferred. If the aortic root will not be replaced then the transverse aortotomy incision is extended on both sides until 3D view of the aortic root appears. That helps surgeons for excision of the severe calcific aortic valve, selection of an appropriate stentless bioprosthesis and insertion simple and/or continuous sutures easily and correctly. A transverse aortotomy is also required to image $3 \mathrm{D}$ shape of the aortic root which is the main condition for resuspention of the prosthetic commissures and to hold a stentless tissue valve in corrected position for prevention of the iatrogenic valve degeneration. An oblique or hockey-stick incision is preferred very seldom, but it could be useful in patients with small aortic root. If the aortic root is replaced it is excised completely and aortic root implantation technique is performed. Reoperation for severe calcific aortic stenosis is not rare in patients with previously coronary 
artery bypass surgery, and patent proximal anastomoses on the ascending aorta can be a serious problem during aortotomy. I have offered a simple aortotomy incision "Reverse U aortotomy" to save proximal anastomoses and if it is necessary to apply direct antegrade cardioplegia through proximal anastomoses [30].

\subsubsection{Excision of the calcific aortic valve}

Aortic valve stenosis appears with fusion of one or both commissures, thickening and retraction of the cusps, and restriction of effective orifice area. Calcific involvement of native aortic valve is the last step which can be widespread very aggressively: aortic annulus, mitral annulus, aortic root, coronary ostia. The typically pathologic findings of calcific aortic stenosis are discrete, focal lesions on the aortic side of the leaflets. The severe form is characterized by diffuse calcification of the aortic root and the deposits involve the sinuses of Valsalva and the ascending aorta (porcelain aorta). The calcification presents as a cauliflower-like mass within the leaflets and often extends deep into the annulus and surrounding tissues. All these contiguous anatomical structures can have adverse affects on the surgical techniques.

A surgically complete decalcification of the aortic annulus is an important point. The flexible continuity of the aortic annulus with sub- and supra-annular tissues is indispensable condition to get better durability and hemodynamics with stentless xenografts, and to avoid from a whole aortic root replacement technique, which hinders surgeons to perform AVR with a stentless xenograft. Surgeons must care 1) not to leave any calcific tissue around the aortic annulus, 2) not to allow fragments of calcium to fall into the left ventricle, 3) not to disrupt the annulus as possible, 4) not to detach the anterior mitral leaflet from the annulus (non-coronary sinus), 5) not to rupture subannular muscular septum (right coronary sinus), 6) not to perforate outside the heart (left coronary sinus).

The calcific aortic valve is excised and trimmed with a scissor leaving a 2-3 mm margin at the annulus if the annular margin of the leaflets are healthy. The frequent scenario is conversely that and extensive calcific involvement of the whole aortic annulus is observed very often. First of all, complete resection of the calcific aortic valve should be performed without any complication listed above. Excision of the calcific leaflets with a scissor is usually unsuccessful and dangerous because of breaking of calcification and falling calcium debris into the left ventricle. The best alternative to remove the diseased tissue is excision all of them with a lancet (number 15). A folded segment of sponge or tampon is not necessary to place in the left ventricle and it hinders to see the cavity and to remove any calcium particle. The easiest excision with the lancet is to perforate the healthy leaflet near the annulus in partial calcified aortic valve or to begin excision at the commissure between the non-coronary and right coronary leaflets in enbloc calcific aortic valve. Cutting of the calcification is begun at the nearest end and the lancet incises the calcified valve from the healthy annular tissue. The sharp edge of the lancet should be headed toward the calcified valve, and cutting is performed just below of calcification. The whole calcified valve must be incised as en-block, without fragmentation. If calcification is very heavy or invaded into the annulus it can be cut with the scissor and then the residual calcifications will be gently crushed and removed with a rounger. After completion of the aortic valve excision, all residual diseased and/or calcified tissue or particles should be 
removed from around the annulus. Before sizing the prosthesis, the left ventricular cavity is flushed and irrigated with saline solution.

\subsubsection{Sizing the stentless aortic bioprosthesis}

The stented prostheses must fit snugly in the annulus, because a very loose or tight fit indicates inadequate effective orifice area (patient-prosthesis mismatch) or oversizing the prosthesis. For the truly measurement of a stented valve, the seizer should be inserted through the aortic annulus and the same (supra-annular) or one number smaller (intra-annular) stented prosthesis must be chosen.

Sizing a stentless bioprosthesis is different from stented valves. The most important phase is the choice of an appropriate stentless bioprosthesis, and measurement of the aortic annulus must be done with the seizer that corresponds to the specific bioprosthesis. The true seizer should be chosen to implant the appropriate tissue valve with the optimum size. If the prosthetic valve is too small, the inflow end obstructs the EOA which increases transvalvular gradient and the outflow end is stretched out with decreased leaflet coaptation which causes more regurgitation. On the other hand, oversizing to fit a larger sinotubular junction leads to buckling of the inflow end which can produce both relative stenosis and regurgitation as well as harmful turbulent flow. How the stentless valves sized and implanted will influence its function and durability in future. The larger surface area of the cusps allows greater coaptation area which reduces the risk of bioprosthesis regurgitation. This relatively larger bioprosthesis can simplify replacement, especially the running sutures for all sinuses. But, it is imperative to avoid over-sizing of stentless valves with the tubular structure achieved by three tabs on the commissures, and if sizing is uncertainty the smaller prosthesis should be implanted.

In normal aortic root, the diameter of the aortic annulus is $10-15 \%$ larger than those of the sinotubular junction and measurement of the aortic annulus is the correct way to choice an appropriate sized stentless valve. However, most patients with calcific aortic stenosis have an abnormal aortic root and the relationship between both diameters is usually altered. In this situation, the diameter of the sinotubular junction is more important because the three commissures of stentless valves are secured at approximately the level of the sinotubular junction if not the full-root replacement technique will be used.

A cylindrical silicon seizer is more practical to measure the true valve size when both the annulus and the sinotubular junction are measured. The rule is that the sinotubular junction should be dominate during measuring and if there is a major difference $(>3 \mathrm{~mm})$ subcoronary implantation technique can be not used because the commissures of stentless valves are pulled outward and cause valvular insufficiency and an alternative technique (root replacement) or stented bioprosthesis must be used. Supra-annular sizing is the best measurement method to choice an appropriate stentless bioprosthesis, especially during single suture line technique. I prefer this more practical way and put the appropriate seizer into the aortic root in supraannular position (not into the annulus) where I put continuous proximal suture line, so I can choice an acceptable size that is equal to the sinotubular junction size or one number larger stentless prosthesis can be chosen if the seizer fits aortic orifice tightly in patients with aortic root enlargement. Trans-annular measurement is adequate to get a fit stentless valve for 
subcoronary implantation in patients with normal aortic root, but preferring one size larger prosthesis is better if full-root replacement technique will be performed or a small aortic root is present. I never suggest to play some traction sutures at the commissures or in the nadir of the annulus to open the aortic orifice. It can be useful during the replacement of a stented valve, but it will be better to release the aortic root in its original shape during sizing stentless valves.

\section{Implantation techniques}

Stentless aortic biologic prostheses can be different in origin: autogenous, homogenous, heterogeneous. Procuring of aortic auto- or homograft is not easy, but production of xenografts is a sufficiently technical supply of the industry for the treatment of aortic valve diseases. All stentless biologic valves can be implanted using different techniques: the subcoronary method, the full root implantation technique, and the root inclusion alternative.

The subcoronary technique is the simplest method for implantation, and either a porcine root can be adapted intra-operatively or a prefabricated tissue valve can be utilized. The main advantages are to avoid the manipulation of coronary ostia and bleeding from suture lines. The disadvantages could be difficulties occurring in the small aortic annulus and calcified aortic root, and possibilities of valve insufficiency by changing the shape of the stentless valve in a diseased aortic root [31]. Subcoronary implantation technique can be performed in two methods: double suture lines (classic) or single suture line (simple) approach.

In classical subcoronary implantation technique, stentless valves are fixed into the host aortic root using double suture lines. The first suture line attaches the inflow site of the stentless bioprosthesis in the left ventricular outflow tract: annular suture line. The second suture line, which is constructed using 1 or 3 continuous sutures, connects the outflow site of the prosthesis with the aortic wall below the coronary ostia: supra-annular suture line. The first suture line consists usually of interrupted sutures, but to reduce cross-clamp and cardiopulmonary times a continuous suture can be preferred [32]. Because the conventional continuous inflow suture line can increase the postoperative heart block risk, an alternative subcoronary technique has been reported in which the inflow suture line is raised at the level of right-non-coronary commissure [33].

The single suture line technique is a simple, quick, safe and reliable method to replace the native aortic valve with a stentless valve. This approach is used for implantation of scalloped new generation tissue valves in supra-annular position and placement of the sutures below or through the annulus should be avoided. Running sutures avoid any prosthetic dead space between prosthetic valve and native aortic wall, and selecting a prosthesis a size larger than the host annulus minimizes the stress on the suture lines. These new generation pericardial valve can have manufactured scalloped design [34] or it can be prepared by trimming away all the extra tissue of the valve inflow side ond scalloping the outflow side [35]. If stentless prostheses are designed with a tubular structure, the tabs on the commissures should be attached to the aortic wall [36]. 
The total root technique requires reimplantation of coronary arteries using the button technique. The main advantages are normal physiological shape of the aortic root and choice of a larger valve in small aortic annulus, and both avoid any patient-prosthesis mismatch. The total root technique also prevents torsions of the commissures which avoiding postoperative prosthetic dysfunction. The main disadvantages are implantation difficulties, requirement of interposition a vascular tubular graft between xenograft and native ascending aorta, and xenograft aortic wall calcification making reoperation difficulty. The learning curve seems to be more pronounced when using the total root technique, whereas single suture line technique may be also performed by young surgeons without any problem. Surgeons decide on their experience and the patient's anatomy pre- and intra-operatively which approach with appropriate stentless bioprosthesis type they will use for AVR. Isolated AVR using the subcoronary technique is the best and easiest way in calcific aortic stenosis and using single suture line technique increases the success of implantation a stentless xenograft.

The direct suture of autologous pericardium to the aortic wall creating a new aortic valve does not need any supporting stent, sewing ring or cuff, allowing to rebuilt 3 symmetrical aortic cusps independent of the geometry of the native aortic valve. Harvesting a circular pericardium about 8-10 $\mathrm{cm}$ in diameter, treating with glutaraldehyde, sizing-cutting-shaping (a trefoil) with a specially designed instrument, and suturing the cut pericardium mounted on a tissue holder are the steps of this technique which does not take more time. The important goal is to reconstruct a newly geometrically symmetric valve and to ensure adequate coaptation with no prolapse. the suture technique is similar to the single suture line technique and running sutures are placed onto supra-annular aortic wall.

\subsection{Subcoronary implantation technique}

This approach is a simple method to implant a stentless bioprosthesis. In spite of the only handicap is the inexperience in this field, geometric thinking is the key point to perform a successful stentless AVR using this approach. A transverse aortotomy helps to image 3D shape of the aortic root which simplifies sizing and implanting a stentless valve. The proximal suture line is performed with the simple interrupted suture technique. This technique requires 18-24 sutures (4/0 Ticron or Polypropylene) which are placed in a circular plane coursing through the aortic annulus (annular suture line) and passed through the inflow end of the stentless valve (subannular suture line). All sutures are passed through the Dacron skirt of the bioprosthesis just below the lowest aspect of the cusps, but the sutures at the native commissures must be passed through the same level of prosthetic commissures to create a geometrical shape without any distortion. It is also important not to injury or perforate the prosthetic cusps when the needles are passed through the skirt of the stentless valve. If the aortic annulus is weakened or destroyed pledgeted sutures (4/0 Ticron) should be placed in subannular position to hold suture securely, which provides satisfactory buttressing effect and repairs annular ruptures. Because xenografts are not as pliable as homografts and its inversion into the left ventricle followed by being pulled up into the aorta may damage the device, I never use this maneuver. The prosthesis is lowered into the aortic root and sutured with its annulus to the aortic annu- 
lus as the baseline line, and all sutures are tied on the skirt. If the prosthesis has three own sinuses, at least the two sinuses facing the native left and right coronary ostia are scalloped out below the level of those recipient coronaries, leaving a 4-5 $\mathrm{mm}$ rim of prosthetic tissue behind. To suture sinuses of bioprosthesis to the native aortic sinuses, three continuous suture lines (5/0 polypropylene) are started in the nadir of each sinus below the native coronary ostia and in the nadir of the non-coronary sinus and progress upward to the top of three commissures (supra-annular suture line), taking care not to buckle the stentless tissue or distort the positions of the commissural posts. The sutures are taken outside the aorta, buttressed with a pledget and tied together. The deep bites of continuous sutures on the aortic sinuses can be transverse or horizontal, but they must be fullthickness at the host aortic wall. The broad bites must be taken on the aortic sinuses of bioprosthesis to avoid any space under device. It is also important to pass the needle well away from the margin of the stentless cusp attachment and not to injury the cusps. If the non-coronary sinus of the stentless valve is kept intact (modified subcoronary technique), it is not necessary to use the third suture, and the distal suture line is completed by running along the top to join the first two sutures. A stay suture (pledgeted 2/0 Ticron) may be placed at the top of each commissure to achieve 3D geometric shape of the device. If it is necessary the tops are trimmed down to the level of the native aorta. The aortotomy is closed with double continuous pledgeted sutures (4/0 polypropylene) beginning from each edge.

\subsection{Single suture line technique}

It is a simple modification of the subcoronary technique and it can be performed according to the design of stentless valve.

Classical subcoronary stentless valves could be implanted with only supra-annular running suture line that places the stentless annulus above and along the native annulus up and around each commissure (Sorin Freedom Solo, CryoLife O'Brien). In this approach, the device should fit the supra-annular area because the aortic trimmed wall of stentless valves is sutured and attached only with proximal supra-annular suture line directly to native aortic sinuses in supra-annular position. Three polypropylene sutures are started at the nadir of each sinus and brought progressively up to each commissural tip with the ends brought outside the aorta for tying (as described above). Because the stentless valve will be placed supra-annular we can choice a 1 or 2 number larger size than the true annular-size and that prevents any transvalvular gradient.

An alternative approach must be preferred in some stentless prostheses designed as having a tubular structure. The outflow orifice is supported by 3 commissural tabs at the distal junction of the leaflets. Inflow implantation is performed with the same running suture line, but the tops of three commissures are equipped at an appropriate location with stay sutures (pledgetless 2/0 Ticron) tied on the outside of the aorta (3f ATS, Shelhigh Superstentless). These tabs are sewn onto the patient's aortic wall, thereby maintaining the tubular integrity of the prosthesis. It is imperative to achieve true-sizing. Should uncertainty arise, the smaller prosthesis should be implanted because larger prosthesis can block a rapid and unobstructed 
opening, whereas to small prosthesis restricts of fully leaflet-opening. The same problem can also occur with an excessive or insufficient distal traction on the tabs.

\subsection{Root inclusion technique}

If the original cylindrical shape of the bioprosthetic root devices wants to be preserved without replacement of the native aortic root to avoid bleeding complication, the root inclusion technique can be chosen. A glutaraldehyde-treated porcine aortic root is implanted inside the patient's aortic root. But this technique is more difficult because both native coronary ostia should be anastomosed to the prosthesis like in classic Bentall procedure. After transverse aortotomy a proximal suture line is performed like the subcoronary technique in a circular plane coursing below the commissures. Appropriate opening for coronary ostia are made by excising the sinuses facing the right and left main coronary ostia and then both are sutured continuously (5/0 polypropylene). The only difference between the root inclusion and subcoronary techniques is that the complete sinotubular junction of the stentless valve is preserved. This method is not used nowadays, and if this technique is preferred it should not be used unless the root is large enough to place 23-mm or larger prosthetic root.

\subsection{Root replacement technique}

Complete replacement of the native aortic root is last preference for those devices. This technique is used mostly during auto- or homograft replacement. A part of the patient's ascending aorta with total aortic root is excised and a new glutaraldehyde-treated porcine aorta with total aortic root is inserted using a single proximal and distal suture lines. Only indication to prefer this approach is an extended pathology through aortic root (endocarditis, annular abscess, porcelain aorta, dissection) if a stentless valve is used. Since the tubular 3D geometry is not altered, its factory-tested performance is not affected by the implantation. All aortic root is excised and both coronary ostia are separated from the root. The valve seizer should fit in the aortic annulus and 1 or 2 number bigger stentless bioprosthesis is chosen. Depending on the anatomical details of the native right coronary artery, the device may be implanted anatomically or rotated to put the porcine left in the patient's right sinus. The proximal suture line is constructed with continuous polypropylene suture or interrupted sutures $(4 / 0)$. The coronary buttons are re-implanted as the standard fashion (5/0 polypropylene). The distal end of the bioprosthesis is usually smaller than the distal native aorta, but it can be not a problem during distal anastomosis (4/0 polypropylene).

\subsection{Direct suture technique of autologous pericardium}

Truly stentless AVR using autologous pericardium sutured directly onto the aortic wall without supporting stents is a safe and feasible alternative with excellent hemodynamics of the aortic root [11]. With the use of specially designed instruments, the sinotubular junction is sized, the pericardium is placed on a base, and a cutting blade of the matching size is placed on top of the pericardium, which cuts it to the required size and shape (a trefoil). The cut pericardium is then mounted on a tissue holder to facilitate suturing it to the aortic wall. The prepared autologous pericardium is then sutured directly onto the aortic wall close to the 
marked annulus using 4-0 polypropylene sutures. Each running suture starting from the base of the leaflet cusp ends at each commissure where it passes through to the outside of the aorta, at which point the knot is tied. The commissures are then securely fixed by passing another mattress suture from inside the commissure to outside the aorta where it is tied. Leaflet symmetry and coaptation are assessed directly at the end of the procedure before closing the aortotomy.

\subsection{Sutureless implantation technique}

Aortic valve replacement with prosthetic heart valves is the treatment of choice for calcific aortic valve stenosis. Stentless valves are the best option with larger EOA and lower transvalvular gradient, but technically the implantations of these valves are more demanding resulting in longer operation times. However, important comorbid conditions in elderly patients referred for aortic valve replacement require alternative treatment options with possible reductions of the extracorporeal bypass and cross-clamp times and reliable hemodynamic features. In order to comply with these requirements, transcatheter (transfemoral or transapical) valves and sutureless surgical valves have been developed. The transcatheter techniques have the advantage of being performed without circulatory bypass but leaving the aortic calcifications in place, thereby resulting in a high degree of paravalvular insufficiency, atrioventricular block and strokes [37]. The surgical approach has the advantage of removing all calcifications and the valves can be optimally implanted, resulting in minimal paravalvular leak with a low incidence of atrioventricular block and strokes; however, it requires cardiopulmonary bypass. The design of sutureless bioprosthesis stems from the intention to offer an alternative to traditional flexible stentless prostheses using conventional open-heart surgery. Sutureless new designed bioprosthesis is a trileaflet bovine or equine pericardial valve mounted on an expandable metal frame in nitinol (equiatomic alloy of nickel and titanium). New designed stentless bioprostheses have several advantages: reducing cross-clamp and cardiopulmonary bypass times, reducing related risk by placing of proximal sutures, less risk of tearing the aortic annulus and wall, avoiding damage of the bundle of His, preventing foreign particle embolization. The primary benefit of this aortic bioprosthesis is the potential for surgeons to provide the same gold standard outcomes of traditional surgical AVR but without the need for sutures, thereby facilitating less invasive or minimally invasive procedures.

The transverse aortic incision is performed $1 \mathrm{~cm}$ above the sinotubular junction to preserve a segment of the ascending aorta above the prosthetic valve. Severe calcific aortic valve is removed and aortic annulus should be decalcified for implantation (it is not necessary a complete decalcification). To ensure the correct positioning and orientation of the prosthesis guide-suture(s) can be used. Avoidance of proximal suture lines makes the procedure easier. The architectural design of this new kind of bioprosthesis allows perfect function after it adapts itself to the aortic root. They have two cylindrical ring segments: 'outflow ring' comprises straight posts designed to support the valve and 'inflow ring' allows the prosthesis to be anchored to the aortic root in the Valsalva sinuses and reaches a final diameter compatible with the aortic root. The configuration of the stentless valve is perfect which allows higher 
hemodynamic performance. There are two types of sutureless aortic bioprostheses in the market.

The Perceval S Aortic Bioprosthesis (Sorin Biomedia Cardio Srl, Sallugia, Italy) has been introduced for minithoracotomy incision [38]. After the device is introduced and parachuted down into aortic annulus and checking corrected position, a balloon dilatation of the inflow ring is performed in the Perceval S valve. If the device is in malpositioning the valve can be quickly removed using the ' $\chi$ movement' and repositioned [39]. Because there are only three number valves $(21,23,25)$, paravalvular leakage can be observed in higher incidence $(4.4 \%$ postoperatively and $4 \%$ during follow-up) which can be a result of either inadequate sizing or due to inappropriate decalcification of the annulus [40]. For an enlarged aorta with a ratio greater than 1.3, the predicted diameter according to body surface area represents a contraindication for this device. Early mortality (total 2.4\%) and late death (total 2.5\%) is acceptable with lower transvalvular gradient $(10.8 \mathrm{mmHg})$ at the first postoperative year [41].

The 3f Enable Aortic Bioprothesis (Model 6000; Medtronic Inc, Minneapolis, USA) is more different and the implantation is more easier: after insertion the device into aortic root in the corrected position, only pour warmer saline $\left(>30^{\circ}\right)$ onto the device to fully deploy the Nitinol frame into its original shape [42]. If malpositioning occurs after complete deployment, rinsing with chilled saline makes the nitinol stent flexible and enhances repositioning until the valve is correctly placed. Early clinical and hemodynamic performances of the $3 \mathrm{f}$ aortic bioprosthesis are similar to those of the regular stentless aortic valves, but both parameters could be inconsistent with the established stentless valves during midterm follow-up: unfavorable mean gradient especially with smaller number $(\leq 23 \mathrm{~mm})$, incomplete left ventricular regression, higher incidence of neurologic complications [43]. However, a multi-center study has shown better early and mid-term results: major paravalvular leakage $2.1 \%$, neurologic events $0.7 \%$, lower mean gradient $(10.2 \mathrm{mmHg}$ ), lower valve-related early mortality rate $(1.4 \%$; total $3.6 \%)$; lower late mortality rate $(1.5 \%$; total $9.6 \%)$, excellent freedom from valve-related mortality at 1-year (96.5\%; hazard ratio $1.6 \%$ / year), lower paravalvular leakage (0.8\%/year) [44].

The analysis of the current outcome of the use of sutureless aortic bioprostheses must take into consideration the preliminary nature of these devices and the relevant implantation learning curve. There are no comparative study analyzing the outcomes of sutureless and stentless bioprostheses, but it can be said that sutureless bioprostheses have better outcome (mortality, neurologic deficit, renal failure, bleeding) than conventional stentless valves in high-risk patients with aortic stenosis (such as older, female, left ventricular dysfunction, calcification in the ascending aorta, previously cardiac operation, pulmonary or renal disease? [45].

\subsection{Transcatheter (transfemoral or transapical) aortic valve implantation}

The approval of transcatheter aortic valve implantation (AVI) represents a fundamental change in the management of calcific aortic stenosis by offering an alternative to traditional surgical AVR in carefully selected patients. Patient-selection is very strict nowadays, and AVI is a reasonable alternative to surgical AVR in adults with severe symptomatic calcific aortic stenosis if they have suitable aortic and vascular anatomy for transcatheter AVI and a predicted 
survival > 12 months [46]. Transcatheter AVI can be prefer in patients with severe calcific aortic stenosis if their aortic valve is trileaflet. There are some exclusion criteria in calcific aortic stenosis: en-block calcification (like unicusp), bicuspid aortic valve, severe massive calcification closely coronary ostia, small aortic annulus $(<18 \mathrm{~mm})$ or large aortic orifice $(>25 \mathrm{~mm})$, thoraco-abdominal aortic or peripheral arterial pathologies. Transapical AVI is the another alternative in patients with calcific aortic stenosis associated thoraco-abdominal aortic or peripheral arterial pathologies.

As experience is gained and technology evolves, new areas will be met with this approaches. The most optional area is bioprosthesis dysfunction requiring reoperation and an attractive option is to use a AVI procedure in which the device is deployed within the previously placed bioprosthesis: valve-in-valve. Valve-in-valve procedures require a large enough bioprosthetic valve inserted at the index operation to prevent patient-prosthetic mismatch with the AVI valve.

\section{Special situations}

Calcific aortic stenosis is a long-term disease and usually associated with other cardiovascular pathologies. Before AVR, all these situations must be reassessmended and case-specific operation procedure and its alternatives must be planned. If we do not think preoperatively that any specific situation needs an intervention intra-operatively, spontaneously home-made resolutions can be also very helpful in the theater when we decide to correct this pathology.

\subsection{Proximal ascending aorta aneurysm}

Severe aortic stenosis is usually combined with proximal ascending aorta aneurysm causing by turbulent flow. The gold standard treatment is composite aortic valve and root replacement. Several surgical teams have devised strategies to construct their homemade composite conduits intra-operatively. It can be a mechanical valved conduit with excellent long-term results [47]. If any contra-indication for anticoagulation therapy, a composite bioprosthetic valved conduit will be the best alternative. Because severe calcific aortic stenosis is often an elderly disease, improved durability of bioprostheses stimulates also their use in the setting of ascending aorta replacement if proximal ascending aorta requires replacement in this population. The concept of composite bioprosthetic valved conduits has also been taken up by the industry and these conduits are already commercially available in different sizes. There are several technical options to allow replacement of the aortic root and ascending aorta using either stented or stentless bioprosthesis [48]. There are basically two alternatives to built a composite graft with a stentless bioprosthesis: the subcoronary technique and the full-root technique.

The subcoronary implantation technique requires a tubular graft and double suture lines for device implantation is necessary. A stentless valve is placed inside a Dacron tube graft leaving a proximal free margin $(3-5 \mathrm{~mm})$ and the proximal suture line of the stentless bioprosthesis is fixed to the graft with a running mattress suture [49]. The free end of the tube graft is then 
sutured to the native annulus with pledgeted interrupted mattress sutures, and following this, the upper circumference of the stentless valve is reimplanted within the tube graft using a second running mattress suture. To avoid the potential drawbacks of a straight cylindrical tube an aortic graft with pseudo-sinuses can be used [50] or David-V procedure using a stentless bioprosthesis can be applied to build new sinuses [51]. I implant firstly tubular synthetic graft using pledgeted interrupted mattress sutures subannularly, and then a stentless valve is implanted using the single suture line technique as described above. The ready-to-use composite biological valved graft is also available in practice currently [The BioValsalva composite grafts (Sulzer Vascutek, Renfrewshire, Scotland, UK)] [52].

The full-root technique is preferred in order to reduce distortion risk leading valve regurgitation or deterioration, but the commercially available stentless porcine aortic root devices are usually too short to replace the host ascending aorta. There are also four alternatives to suture a stentless conduit directly to the distal ascending aorta with extended tubular devices: extended version of stentless porcine aortic root bioprosthesis, direct anastomosis after extensive mobilization of the host aorta, interposition of a Dacron tube graft, and total xenopericardial valved conduit. The availability of extended root xenograft is extremely limited, but this approach can achieve an anastomosis between xenograft and the distal ascending aorta [53]. Primary end-to-end anastomosis might prevent the need for graft interposition, but extensive mobilization of the aortic arch and its branches can be dangerous and some tension might be left at the distal anastomosis with a risk of late dehiscence and false aneurysm development [54]. The most practical technique appears to be the insertion of a Dacron tube graft between the xenograft root and the native distal ascending aorta [55]. There is a new bioprosthetic conduit, constructed using individual non-coronary porcine cusps, which are fitted on a scalloped shaped tubular bovine pericardium [56]. The $15 \mathrm{~cm}$ long pericardial cuff is long enough to facilitate the anastomosis between the conduit and the remaining distal aorta. If mid- or long-term results will confirm excellent results, this option will be an attractive alternative to the others techniques.

\subsection{Small aortic annulus}

Aortic valve replacement with a small stented prosthetic valve is technically straightforward and frequently performed, but it may result in patient-prosthesis mismatch and a high residual outflow gradient, which is significant risk factor for early mortality [57]. Patient-prosthesis mismatch is associated with an increase in all-cause and cardiac-related mortality over longterm follow-up, and current efforts to prevent prosthesis-patient mismatch should receive more emphasis and a widespread acceptance to improve long-term survival after AVR [58]. When the aortic annulus diameter is less than $20 \mathrm{~mm}$, a relatively high transvalvular velocity has to be expected after valve replacement. In these cases, a stentless bioprosthesis with/ without aortic root enlargement would provide better hemodynamic results than stented valves.

For severe small aortic root with small aortic annulus, a xenograft root replacement can be the first alternative and this technique avoids the aortic annulus enlargement, but it can be problematic because of reimplantation of the coronary arteries, calcified aorta and/or coronary 
ostia, or prolonged operation times. The full-root replacement technique is technically more demanding, but it prevents residual gradient postoperatively, and if one number larger conduit is selected the possible largest orifice area will be gained. Subcoronary techniques with/without intact non-coronary sinus can be also used in these patients with excellent hemodynamics in smaller valve sizes and appropriate device can be implanted safely and easily [59].

Another alternative technique is aortic annulus enlargement to prevent patient-prosthesis mismatch and a two-size-larger prosthesis could be inserted. The most commonly used technique is enlargement of the aortic annulus with a biologic or synthetic patch which can be performed in different approach [60]. A modification of the Manouguian technique has been introduced for aortic annulus enlargement without using a patch [61]. A tubular aortic bioprosthesis of one or two sizes larger than the size of the native annulus is prepared for modified subcoronary implantation technique and non-coronary sinus wall be kept intact. The prosthesis is sutured directly on the enlarged annulus after the aortic incision is extended through the commissure, and the aorta is closed directly with the mural wall of the tubular xenograft.

\subsection{Porcelain aorta}

The scope of porcelain aorta ranges from isolated plaques to the circumferential calcification of the ascending aorta. Typically, a heavily calcified ascending aorta with calcific aortic stenosis involves aortic annulus, aortic valve, aortic root and ascending aorta ( \pm distal aortic segments). This scenario is associated with higher operative mortality and morbidity than isolated severe calcific aortic stenosis. A more recent study have been demonstrated a link between arteriosclerotic changes in aortic valve and ascending aorta [62]. This study compared healthy patients with severe aortic stenosis patients shows that the prevalence of aortic root calcification $(26 \%$ versus $54 \%$; $p=0.008)$ and of atheroma in the ascending aorta $(7 \%$ versus $24 \%$; $p<$ 0.001 ) are higher in aortic valve disease patients and patients coexisting coronary artery disease have more extensive arteriosclerotic changes in the thoracic aorta compared with those with aortic stenosis alone and control subjects.

The operative management of severe calcific aortic stenosis with porcelain aorta can be difficult and complex because of difficulty of clamping the ascending aorta, aortotomy, supra-annular sutures, or aortic root replacement, and the risk of calcific embolization of major branches (coronary, carotid, or other arteries), aortic dissection. Digital palpation with a lowered systemic blood pressure or epiaortic sonographic evaluation can be used to confirm that there is a softer spot in the aortic arch for cannulation intra-operatively. If there is no any healthy site on the distal ascending aorta or aortic arch for regular arterial cannulation (34\%), alternative arterial cannulation should be performed through innominate $(8 \%)$, axillary $(24 \%)$ or femoral (34\%) artery [63]. There are several alternatives to perform AVR: standard replacement, endarterectomy for calcified porcelain aorta, no touch technique under circulatory arrest (no cross-clamp, no endarterectomy, no ascending aorta replacement), total replacement of the ascending aorta replacement (with/without circulatory arrest), apico-aortic valved conduit, transcatheter AVI. I prefer standard AVR if it is possible, if not I perform David-V total 
ascending aortic replacement with a stentless bioprosthesis [47]. Last decade, ascending aortic replacement is the most preferred method for the treatment of porcelain aorta, but transfemoral [64] or transapical [65] AVI will replace the first choice of the treatment in this decade. These alternatives demonstrate significant advantages (especially very low incidence of neurological events, avoidance of cardiopulmonary bypass and circulatory arrest) in comparison to other conventional techniques in the setting of severe aortic calcification.

\subsection{Concomitant severe coronary artery disease}

Many patients with moderate or severe calcific aortic stenosis have significant coronary disease, suggesting that the degenerative changes of the aortic valve leading to aortic stenosis may be part of a similar arteriosclerotic process. Coronary lesion can be also in different coronary arteries or massif calcification involves into coronary ostia. Combined surgical treatment is the main modality, but percutaneous coronary intervention is safer in patients undergoing transcatheter AVI, or in patients with high risk (high comorbidities, reoperation, pericardial adhesion). Because hypercholesterolemia is related to increased risk of aortic valve calcification in patients with aortic stenosis, preventive treatment of hypercholesterolemia could play an important role to decrease or inhibit development of aortic valve calcification [66].

\subsection{Concomitant hematologic disease}

The best opportunity to improve the treatment of any hematologic disease or to prevent any complication aggravating by hematologic pathologies is avoidance from prosthetic foreign devices. Autologous tissue is the only biologic material preparing prosthetic valve, but that can be limited because of pericardial pathologies, inadequate surgical experience or technical problems. Mechanical valves have life-long durability with some possible hematologic complications such as thrombo-embolism, warfarin related hemorrhage, heparin induced thrombocytopenia, hemolysis. Prosthetic foreign material can also aggravate hematologic diseases. To decide which prosthesis can be the acceptable choice for AVR in patients with hematologic pathology is depend on patient's characteristics and patient-by-patient analysis is required. Biomaterials seem better than mechanical prostheses, and stentless aortic bioprostheses are the best alternatives because of absence of a rigid stent, biodynamic characteristics, larger EOA with lowest transvalvular obstruction, unnecessariness of anticoagulation, which might decrease hematologic complications. I prefer stentless xenografts for AVR in patients with severe hematologic pathologies [67].

Postoperative thrombocytopenia is a transient phenomenon, self-recovering after a few days without any treatment and without any observed recurrence in late follow-up. Microhemodynamic effects of the prosthesis structure or depending on the implantation technique and/or specific chemical preparations of biological prosthesis tissue could act as a trigger for the post-replacement thrombocytopenia. It seems to be possible that transient unspecific activation of platelets result in diffuse consumption and lower platelet levels. The reason for this phenomenon is unknown and the use of consistent monitoring is necessary to prevent severe falls in platelet count. It seems unrelated to the type of aortic bioprosthesis and I have 
not observed this phenomenon only in stentless pericardial valves, but also in different bioprostheses [68]. However, thrombocytopenia after implantation of the stentless pericardial xenografts can develop more common and becomes dangerous for the patient $[69,70]$.

\section{Surgical-technical complications}

In spite of all implantation techniques of different stentless bioprostheses are demanding and require an aortic valve surgical experience, some situations can make trouble AVR intraoperatively or impair operative outcomes in the early postoperative period. Every surgeon must be aware of these troubles and keep in mind case specific technical solutions in the theater.

\subsection{Severe annular calcification}

To replace the diseased aortic valve in patients with calcific aortic stenosis is a serious intervention because of extensive calcification. Debridement of all calcium deposits back to soft tissue improves seating of stentless prostheses in supra-annular position and provides better performance, and may be, protects devices early calcification. I always prefer deep debridement and decalcification of all around structures. If there is no any damage on the annulus, I implant a stentless valve with the single suture technique (supra-annular implantation); if not, I prefer the classic subcoronary technique and use pledgeted sutures in subannular position to repair defects. Calcification after stentless valve implantation is complicated if a stentless bioprosthesis is implanted in young patient: faster calcification in homografts has been reported compared with xenografts [71].

\subsection{Conduction disturbances}

Permanent of transient conduction defects are well-known complications of aortic valve surgery [72]. Higher degree atrioventricular blocks are often reversible and disappear before discharge from the hospital. Approximately $5 \%$ of patients undergone isolated AVR require permanent pacemaker implantation. Risk factors can be patient-specific: bicuspid aorta, annular calcification, hypertension, preexisting conduction disturbances, coronary artery disease. Surgeon-specific risk factors cause mostly mechanical injury of the atrioventricular conduction pathways during aortic valve surgery: annular decalcification, deep suture placement, suturing techniques, pressure on the conduction tissue. Atrioventricular block generally results from trauma to the atrioventricular node or His bundle in the region of membranous septum and right trigone beneath the non-coronary - right coronary cusps commissure. The continuous inflow suture line is the most common cause for atrioventricular block because this suture line is placed below each commissure in a horizontal plane based on the level of the nadir of the attachments of the native aortic valve leaflets to the native aortic valve annulus. Raising the continuous inflow suture line below non-coronary - right coronary commissure prevents such conduction complication. Interrupted inflow sutures are also safer than continuous technique. The best approach is the single suture line technique which does not need any inflow suture line. 


\subsection{Coronary insufficiency}

Coronary flow complications are uncommon after stentless AVR, in spite of calcific aortic valve stenosis appears often with coronary ostia calcification with/without coronary artery disease. Myocardial ischemia developing after AVR can develop due to several reasons. Uniform adequate myocardial preservation during operation is the main preventive strategy. Coronary artery bypass grafting should be added aortic valve surgery if any coronary artery stenosis is proved angiographically before surgery. Technical or pathologic factors must also keep in mind. Extensive calcific involvement of coronary ostia or any calcific particle embolization can block antegrade coronary blood flow postoperatively. Endarterectomy or coronary artery bypass grafting should be performed if not any coronary lesion is proved. Decalcification of the aortic root may be well without any aggressive manipulation on coronary ostia, but rupture around coronary ostia can be fatal. Implantation techniques can damage coronary blood flow due to technical errors. Besides a learning curve for these more complex procedures, other factors that could potentially contribute to excess myocardial ischemia or bleeding causing coronary ostia complications. Technical problems can occur mostly during the aortic root replacement with stentless xenografts. This type of coronary insufficiency is uncommon and more often affects the right coronary artery [73]. Coronary buttons are prepared for suturing to xenografts, but they can be damaged because of extensive cutting, dissection, or aggressive decalcification of buttons. Severe tension on the button anastomoses can cause bleeding, rupture, kinking or obstruction. Preventive maneuvers are recognition of coronary orientation, routine xenograft rotation, adequate coronary button mobilization, oversizing xenograft. The subcoronary implantation is more secure procedure than the root replacement technique and technical complication causing coronary problems can occur very seldom if running sutures bite very close to the coronary ostia.

\subsection{Dehiscence}

Partial or severe dehiscence of aortic prosthetic valves is a serious, but very rare complication. Complete dehiscence occurs with sudden death and it is not seen during practice life. Demand on the severity of dehiscence, the clinic scenario can be variable. Limited dehiscence can be silent and stable, more serious dehiscence shows some signs and unstable. If the aortic root replacement technique is preferred dehiscence can be very small at the proximal or distal suture line which presents bleeding, hematoma or massif hemorrhage. Dehiscence observed after the subcoronary implantation technique is associated with aortic regurgitation, but using obliterating sutures prevent usually this complication. In the aortic root inclusion technique, the dead space between native and donor aortas might be prevented adequate fusion of the walls and healing of the anastomoses, which is observed mostly in non-coronary sinus [74]. Any symptomatic dehiscence investigated by echocardiography intra- or early postoperatively should be repaired and a reoperation should be performed immediately. In the absence of valve dysfunction, progressive dehiscence, or the development of thrombus a reoperation can be not necessary and conservative management will be safe during early- and long-term follow-up [75]. 


\subsection{Progressive sinotubular junction dilatation}

This late postoperative complication is observed in some stentless xenografts when they are implanted with the subcoronary technique. Currently, little is known of the diastolic properties of stentless valves that affect stress and strain on leaflets and, hence, their durability. Despite similar systolic performances, stentless prostheses behave differently during diastole. The commissures of the stentless bioprostheses have to follow the dimensional changes of the native aortic root not only in a cyclic mode but also the increase of the aortic diameter [76]. This change pulls apart the commissures leading to reduction of coaptation area of the cusps and late aortic insufficiency develops. Aortic regurgitation is often mild or moderate depending on bioprosthesis type, especially in old generation, but re-operation rate is low. In a pressurized aortic root model, a series of in-vitro tests is conducted to determine how stentless valves behave in diastole, and how they adapt to different annulus-to-sinotubular junction (STJ) ratios [77]. Pericardial prostheses built to mimic a cylinder (ATS 3F and Sorin Solo) showed the greatest tolerance to STJ dilatation and a larger coaptation surface, but also a tendency to roll in on themselves in an italic S-shape if oversized. Valves built to mimic native aortic leaflets (porcine Prima Plus and Medtronic Freestyle) showed a reduced tolerance to STJ dilatation, resulting in regurgitation and a smaller coaptation surface, but also a reduced tendency to roll if oversized.

A significant difference of tolerance against aortic regurgitation with respect to dilatation of the sinotubular junction was found in an in vitro study: fresh porcine aortic root (higher) $>$ fresh porcine pulmonary root $>$ stentless porcine bioprosthesis (lower) [78]. This loss of adaptability may be related to the glutaraldehyde fixation leading stiffness and shrinkage of the bioprosthetic leaflets which leaves inadequate coaptation reserve. An increase of sinotubular junction diameter of more than 32\% for the Toronto SPV and 43\% for Medtronic Freestyle stentless valves results in a distinct loss of leaflet coaptation and causes aortic regurgitation.

New generation of pericardial stentless valves developed for subcoronary implantation have larger coaptation area than those old generation or porcine stentless valves, which may provide better adaptability to adverse changes in root dimensions [79]. With massif progressive stepwise dilatation at sinotubular junction level, the free edges of the leaflets are stretched wider and a triangle-shaped central coaptation defect will occur. For the 3F Aortic valve regurgitation started at approximately $156 \%$ of the labeled valve size and $145 \%$ for the Sorin Solo valve. The increased tolerance of pericardial bioprostheses may improve long-term valve performance, but durability of these valves may be affected by the redundant leaflet tissue leading increase of leaflet stress and degeneration.

To overcome this disadvantage of stentless valves, a slight oversizing of the devices may result better valve competence and hemodynamic efficiency compared to size-for-size implantation. Sizing with a supra-annular seizer is helpful to find the largest stentless valve number which is minimum equal to the sinotubular junction diameter in patients with healthy aortic root. The single suture line technique is fixed prosthetic sinuses onto the native aortic wall to prevent any leakage or stretching. 


\subsection{Reoperation of a stentless aortic bioprosthesis}

Stentless aortic valve reoperations may become more common as these bioprostheses reach the limits of their durability, which are a challenging procedure with an increased risk of death [80].The current generation of stentless valves have been implanted since the early 1990s and are therefore starting to reach the limits of their durability. Reoperation for stentless valves is a complex procedure, especially root inclusion or full-root replacement was preferred. The risk of trauma to the coronary ostia, aortic wall, aortic annulus, anterior mitral valve, and membranous septum can all occur when severe adhesions or calcification are present around the stentless valve. Reoperation after a stentless valve is more complex than after a stented tissue or mechanical valve if root replacement techniques is used in the first operation. However, reoperation of subcoronary implanted stentless bioprosthesis is easier than any stented prosthesis because cutting only the suture line is enough to remove the degenerated bioprosthesis. Valve-in-valve replacement with transfemoral [81] or transapical [82] AVI is a more conservative alternative strategy for re-replacement of degenerated xenograft in high risk patients.

\section{Clinical results}

\subsection{Survival}

Risk of death is highest immediately after AVR in patients with severe aortic stenosis, decreased to its nadir approximately 1 year postoperatively (early hazard period), and then gradually increased (late hazard period) [83]. From approximately 2 years after operation, survival is similar to that of matched population estimates. Early outcome of patients with aortic stenosis after AVR is primarily influenced by severity of the stenosis, left ventricular hypertrophy and dysfunction at operation. Severity of aortic stenosis, severe left ventricular hypertrophy, left ventricular dysfunction, older age and patient-prosthesis mismatch worsen also long-term survival. Furthermore, stentless AVR requires longer cross-clamp and cardiopulmonary bypass times.

Several meta-analysis studies confirm that stentless AVR does not worsen the early and late outcome when compared to stented bioprostheses. Also, longer operation times do not have any adverse effect on the intra-operatively mortal complications and postoperative outcomes. Contrarily, early recovery of hemodynamic malfunctions caused by calcific stenotic native aortic valve brings better early and late outcomes.

Hospital mortality rate of stentless bioprostheses is lower than those of stented xenografts $[84,85]$. Early hospital or 30-day mortality is similar between stentless and stented bioprosthesis replacement in a meta-analysis $(3.2 \%$ versus $2.4 \% ; \mathrm{p}=0.39)$, and further analysis of 30 days mortality is subgroups included predominantly patients with aortic stenosis shows still no significant difference between two types of aortic bioprosthesis ( $3.7 \%$ versus $2.6 \%$; $=0.44$ ) [86]. Only one retrospective multicenter study has shown if stentless valves are used only in selected patients (older age, female, full-root replacement) the 30-day mortality is increased 
when compared with stented valves $(7.5 \%$ versus $3.3 \%$; $=0.026)$, but if stentless valves are used widely there is no significant difference in operative mortality between stentless and stented groups [87].Using autologous pericardium does not worse the early hospital outcome and early mortality is not seen [11].

Several studies showed an improved mid-term ( $<10$ years) survival after stentless AVR compared to stented valves $[88,89]$. A meta-analysis shows that mortality at the first year is lower after stentless aortic bioprosthesis replacement than stented bioprosthesis, but not significant: $7.5 \%$ versus $8.9 \% ; \mathrm{p}=0.73$ [15]. Another meta analysis also confirm no significant difference for valve-related mortality between stentless and stented xenograft replacement in the first postoperative year [86]. Lehmann and associates [89] showed in a randomized trial that 8 -year survival was $78.1 \% \pm 3.8 \%$ stentless versus $66.7 \% \pm 4.9 \%$ stented $(p=0.03)$. They concluded that there was no difference in survival when compared stentless patients with an age-matched German control population.

The long-term results ( $\geq 10$ years) with stentless valves are excellent [90]. The overall 10- and 15-year survival rates of Freestyle bioprosthesis are $60.7 \%$ and $35 \%$, respectively [91]. The 10year actuarial survival $(44.1 \% \pm 4.3 \%$ in subcoronary, $47.3 \% \pm 8.15$ in full-root, and $45.4 \% \pm$ $13.7 \%$ in root inclusion groups; $\mathrm{p}=0.89)$ and freedom from valve-related death $(94.5 \% \pm 2.9 \%$ in subcoronary, $92.9 \% \pm 5.8 \%$ in full-root, and $87.8 \% \pm 12.5 \%$ in root inclusion groups; $\mathrm{p}=0.17$ ) are similar between implants techniques with the Freestyle stentless bioprosthesis [92]. Longer follow-up (> 15 years) of stentless valves is also necessary to compare the excellent results of stented valves to establish that stentless xenografts are significantly superior than stented devices.

\subsection{Durability}

The rate of structural valve deterioration increases over time, especially after the initial 7 to 8 years after implantation. Structural degeneration increases long-term events and the rate of failure is $<1 \%$ at 10 years in patients older than 65 years [93]. Pericardial valves might be better than porcine valves, but all newer-generation bioprostheses are more durable. In spite of the rate of failure of any bioprosthesis decreases with the age of the patient at the time of implantation $(<10 \%$ at 10 years in patients older $>70$ years), the number of implanted stentless xenografts has increased due to improved hemodynamic performance and long-term durability during last decade. Theoretically, xenogenic stentless aortic valves have better durability than stented valves. But in real life, the freedom rate from structural valve deterioration is similar in stentless and stented bioprostheses (>90\% at 10 years). CryoLife O'Brien and St Jude Toronto SPV valves have worst durability compared the other stentless valves (Medtronic Freestyle, Edwards Prima, St Jude Biocor, Sorin Pericarbon and Solo, ATS 3f).

When we focus on the implantation techniques, there are very rare papers in the literature. The overall freedom from reoperation with Freestyle stentless bioprosthesis is $91.0 \%$ and $75.0 \%$ at 10 and 15 years, whereas freedom from reoperation for structural valve deterioration was $95.9 \%$ and $82.3 \%$, respectively. At 10 and 15 years, freedom from reoperation for structural valve deterioration is $94.0 \%$ and $62.6 \%$ for patients $<60$ years of age and $96.3 \%$ and $88.4 \%$ for patients $\geq 60$ years of age $(p=0.002)$ [90]. The actuarial freedom from reoperation $(91.7 \% \pm 3.5 \%$ 
in subcoronary, $92.3 \% \pm 6.0 \%$ in full-root, and $92.0 \% \pm 10.7 \%$ in root inclusion groups; $\mathrm{p}=0.82$ ) and from structural valve deterioration $(97.0 \% \pm 2.2 \%$ in subcoronary, $96.0 \% \pm 4.5 \%$ in full-root, and $90.9 \% \pm 11.2 \%$ in root inclusion groups; $\mathrm{p}=0.54$ ) are similar between implants techniques with the Freestyle stentless valves [91].

The truly stentless autologous pericardial aortic valve may be better choice in patients who cannot or do not want to take anticoagulation, especially young population, because excellent long-term durability and easier reoperation, which is technically undemanding compared to other stentless bioprostheses. The use of autologous pericardium avoids any immune reaction between the host and the implanted valve, and minimizes tissue calcification and pannus formation, which are important causes of structural valve deterioration. The absence of a stent and sewing ring is also helpful for long-term durability with a freedom from structural valve deterioration of $100 \%$ at 7.5 years [11]. Long-term durability seems better than the other bioprostheses because it has been reported that there is no calcification, no structural dysfunction on the autologous pericardium used for aortic leaflet extension at 13 years [94]. Reoperation must be easier because there is no calcification on the aorta and pericardial aortic valve.

\subsection{Echocardiographic outcomes}

The advantage of stentless xenografts is providing a greater EOA index for a given valve size, which results lower transvalvular gradients compared with stented valves. These improvements have been reported in a meta analysis: lower mean aortic valve gradient $(-3.57 \mathrm{mmHg}$; $\mathrm{p}<0.01)$, lower peak gradient $(-5.8 \mathrm{mmHg} ; \mathrm{p}<0.01)$, but higher EOA index in stentless group compared with the stented [15]. It has been shown in an experimental porcine model that the annular cross-sectional area of stentless valves is significantly larger than stented valves [23]. The EOA will increase after first postoperative year in stentless valves and significant differences in mean and/or peak pressure differences between stentless and stented valves will continue during long-term follow-up [95,96].

The Freedom SOLO stentless bioprosthesis with all size-number has a lower mean $(10.6 \pm 3.6$ $\mathrm{mmHg})$ and peak $(15.9 \pm 9.1 \mathrm{mmHg})$ transvalvular gradient at discharged, and below $10 \mathrm{mmHg}$ in all sizes (21-27 $\mathrm{mm}$ ) at the first postoperative year [97]. The similar results have been shown by other groups: lower mean gradient $(6.7+/-4.1 \mathrm{mmHg})$ and a significant regression of left ventricular hypertrophy (23\%) at 12 months [98].

3f aortic bioprosthesis has a satisfactory hemodynamic performance with substitutes larger than $23 \mathrm{~mm}(<10 \mathrm{mmHg})$, but smaller valves have a significant higher mean transvalvular gradient at the 4-postoperative year $(18 \mathrm{mmHg}$ for $21 \mathrm{~mm}$ and $14 \mathrm{mmHg}$ for $23 \mathrm{~mm}$ devices) [36]. The left ventricular mass index decreases during follow-up (showed 18\% regression), but cannot reach the normal range, especially with small devices. In another study with a mean valve size $26.0 \pm 1.9 \mathrm{~mm}$ has shown that the mean transvalvular gradient of $3 \mathrm{f}$ bioprostheses has increased at 5 years $(15.2 \pm 5.3 \mathrm{mmHg})$ [99].

The Edwards Prima Plus stentless valve bioprosthesis is a porcine aortic root cylinder and is associated with high early peak and mean transprosthetic gradients $(37 \pm 16$ and $18 \pm 8 \mathrm{mmHg}$, 
respectively), which regress with significant improvement at 1 year $(25 \pm 7$ and $12 \pm 4 \mathrm{mmHg}$, respectively) and concomitant regression of left ventricular hypertrophy [100]. The Edwards Prima Plus stentless xenograft implanted with intact non-coronary sinus technique prevents the geometry of the device and has excellent long-term result (mean gradient $<10 \mathrm{mmHg}$ ) in all sizes (21-29 $\mathrm{mm})$ [101].

There are some studies showing different results regarding transaortic gradient, which might be a result of different stentless xenografts or implantation methods. There is no any significantly difference among implantation techniques when the same stentless xenograft is used with different implantation techniques, but full root $(4.8 \mathrm{mmHg})$ or root inclusion technique $(5.1 \mathrm{mmHg})$ has lower mean transvalvular gradient than the subcoronary technique $(7.2 \mathrm{mmHg})$ [102]. Transvalvular gradient and EOA are significantly worse in subcoronary groups in the first postoperative period, but this difference will be insignificant due to decreasing EOA and root inclusion approach will have the worst hemodynamics at 10th postoperative year [90].

Stentless valves are the best choice in patients with small aortic annuli than large annuli, because the lower transaortic pressure difference of stentless valves has no any significant advantage over stented bioprostheses if a valve larger than $23 \mathrm{~mm}$ will be used [103]. The difference will be significantly when a stentless valve sized $23 \mathrm{~mm}$ is used (Freestyle inclusion $11 \mathrm{mmHg}$ versus Perimount $25 \mathrm{mmHg}$ ) [21]. The Freedom SOLO stentless bioprosthesis seems to have better hemodynamics even in patients received a small aortic bioprosthesis with a lower mean transvalvular gradient $(9 \pm 2.9 \mathrm{mmHg}$ for $21 \mathrm{~mm}$, and $7.6 \pm 5 \mathrm{mmHg}$ for $23 \mathrm{~mm}$ ) [97].

Physically active patients might benefit from stentless valves. Several studies showed that the gradient difference between different aortic stentless and stented bioprostheses of similar size with different implantation techniques increased significantly at each exercise level in favour of stentless valves [104-105106].

\section{Conclusion}

Aortic valve replacement means that native valve disease is replaced with prosthetic valve inadequacy affected by prosthetic valve hemodynamics, durability, and thrombogenicity. Stentless bioprostheses have better hemodynamic properties because of larger effective orifice area, better coronary flow, lower transvalvular gradient and better left ventricular mass regression than stented bioprostheses. They have also better biomechanical properties and the preserved distensibility may diminish stress considerably. Valve-related morbidity and structural valve degeneration are not worse than stented valves, but their implantation is demanding and required experience in this field. Although experienced centers give excellent results with stentless xenografts, most surgeons also prefer a stented xenograft to keep the procedure quick, safe, and simple. But, there is a trend to favor stentless valves nowadays because these valves provide larger effective orifice area, lower transvalvular gradients and excellent hemodynamics which stimulate rapid and effective reduction in left ventricular 
hypertrophy. It seems that the usage of stentless valves has more advantages in patients with impaired left ventricular function, small aortic, or aortic root abscess or more active patients. In future, using of stentless valves will increase with simpler implantation techniques, increased surgical experience, new design of prostheses, may be, using sutureless valves.

\section{Author details}

Kaan Kirali*

Address all correspondence to: imkbkirali@yahoo.com

Depertment of cardiovascular surgery, kosuyolu heart and research hospital, Istanbul, Turkey

\section{References}

[1] Ross DN. Homograft Replacement of the Aortic Valve. Lancet 1962;2:487.

[2] Barrat-Boyes BG. Homograft Aortic Valve Replacement in Aortic Incompetence and Stenosis. Thorax 1964;19:131-150.

[3] Binet JP, Duran CCT, Carpentier A, Langlois J. Heterologous Aortic Valve Transplantation. Lancet 1965;2:1275-1276.

[4] Sievers HH, Lange PE, Bernhard A. Implantation of a xenogenic Stentless Aortic Bioprosthesis. First Experience. Thoracic Cardiovascular Surgeon 1985;33(4):225-226.

[5] David TE, Pollick C, Bos J. Aortic Valve Replacement with Stentless Porcine Aortic Bioprosthesis. Journal of Thoracic Cardiovascular Surgery 1990;99(1):113-118.

[6] Pelletier LC, Carrier M. Bioprosthetice Heart Valves: 25 Years of Development and Clinical Experience. In: Acar J and Bodnar E (eds). Textbook of Acquired Heart Valve Disease. ICR Publishers: London; 1995. p920-956.

[7] David TE. Stentless Bioprosthetic Valves. In: Acar J and Bodnar E (eds). Textbook of Acquired Heart Valve Disease. ICR Publishers: London; 1995. p957-964.

[8] Takkenberg JJM, Klieverik LMA, Schoof PH, van Suylen R-J, van Herwerden LA, Zondervan PE, Roos-Hesselink JW, Eijkemans MJ, Yacoub MH, Bogers AJ. The Ross Procedure. A Systematic Rewiev and Meta-Analysis. Circulation. 2009;119(2): 222-228.

[9] El-Hamamsy I, Clark L, Stevens LM, Sarang Z, Melina G, Takkenberg JJ, Yacoub MH. Late Outcomes Following Freestyle versus Homograft Aortic Root Replace- 
ment. Results from a Prospective Randomized Trial. Journal of American College of Cardiology 2010;55(4):368-376.

[10] Love JW. Autologous Pericardial Reconstruction of Semilunar Valves. Journal of Heart Valve Disease 1998;7(1):40-47.

[11] Chan KMJ, Rahman-Haley S, Mittal TK, Gavino JA, Dreyfus GD. Truly StentlessAutologous Pericardial Aortic Valve Replacement: An Alternative to Standard Aortic Valve Replacement. Journal of Thoracic Cardiovascular Surgery 2011;141(1):276-283.

[12] Frost MW, Funderl JA, Klaaborg KE, Wierup P, Sloth E, Nygaard H, Hasenkam JM. Leaflet Opening and Closing Dynamics of Aortic Bioprostheses. Journal of Heart Valve Disease 2010;19(4):492-498.

[13] Revanna P, Fisher J, Watterson KG. The Influence of Free Hand Sturing Technique and Zero Pressure Fixation on the Hemodynamic Function of Aortic Root and Aortic Valve Leaflets. European Journal of Cardiovascular Surgery 1997;11(2):280-286.

[14] Cohen G, Christakis GT, Joyner CD, Morgan CD, Tamariz M, Hanayama N, Mallidi H, Szalai JP, Katic M, Rao V, Fremes SE, Goldman BS. Are Stentless Valves Hemodynamically Superior to Stented Valves? A Prospective Randomized Trial. Annals of Thoracic Surgery 2002;73(3):767-775.

[15] Kunadian B, Vijayalakshmi K, Thornley AR, de Belder MA, Hunter S, Kendall S, Graham R, Stewart M, Thambyrajah J, Dunning J. Meta-analysis of Valve Hemodynamics and Left Ventricular Mass Rregression for Stentless versus Stented Aortic Valves. Annals of Thoracic Surgery 2007;84(1):73-78.

[16] Perez de Arenaza D, Lees B, Flather M, Nugara F, Huseybe T, Jasinski M, CisowskiM, KhanM, HeneinM, GaerJ, GuvendikL, BochenekA, WosS, LieM, VanNootenG, PennellD, PepperJ. Randomized comparison of Stentless versus Stented Valves for Aortic Stenosis: Effects on the Left Ventricular Mass. Circulation 2005;112(17): 2696-702.

[17] Dunning J, Graham RJ, Thambyrajah J, Stewart MJ, Kendall SW, Hunter S. Stentless vs Stented Aortic valve Bioprostheses: A Prospective Randomized Controlled Trial. European Heart Journal 2007;28(19):2369-2374.

[18] Gulbins H, Reichenspurner H. Which Patients Benefit from Stentless Aortic Valve Replacement? Annals of Thoracic Surgery 2009;88(6):2061-2068.

[19] Rabus MB, Kirali K, Kayalar N, Tuncer EY, Toker ME, Yakut C. Aortic Valve Replacement in Isolated Severe Aortic Stenosis with Left Ventricular Dysfunction: Long-term Survival and ventricular Recovery. AnatolianJournalofCardiology2009;9(1):41-46.

[20] Borger MA, Carson SM, Ivanov J, Rao V, Scully HE, Feindell CM, David TE. Stentless Aortic Valve are Hemodynamically Superior to Stented Valves During Mid-term Fol- 
low-up: A Large Retrospective Study. Annals of Thoracic Surgery 2005;80(6): 2180-2185.

[21] Williams RJ, Muir DF, Pathi V, MacArthur K, Berg GA. Randomized Controlled Trial of Stented and Stentless Aortic Bioprostheses: Hemodynamic Performance at 3 Years. Seminars Thoracic Cardiovascular Surgery1999;11(4 Suppl 1):93-97.

[22] Narang S, Satsangi DK, Banerjee A, Geelani MA. Stentless Valves versus Stented Bioprotheses at the Aortic Position: Midterm Results. Journal of Thoracic Cardiovascular Surgery 2008;136(4):943-947.

[23] Ali A, Halstead JC, Cafferty F, Sharples L, Rose F, Coulden R, LeeE, DunningJ, ArganoV, TsuiS. Are Stentless Valves Superior to Modern Stented valves? A prospective Randomized Trial. Circulation 2006;114(1 Suppl):I535-I540.

[24] Funder JA, Ringgaard S, Frost MW, Wierup P, Klaaborg KE, Hjortdal V, NygaardH, HasenkamJM. Aortic Root Distensibility and Cross-sectional Areas in Stented and Subcoronary Stentless Bioprostheses in Pigs. Interactive Cardiovascular Thoracic Surgery 2010;10(6):976-980.

[25] Ennker JAC, Albert AA, Rosendahl UP, Ennker IC, Dalladaku F, Florath I. Ten-Year Experience With Stentless Aortic Valves: Full-Root Versus Subcoronary Implantation. Annals of Thoracic Surgery 2008;85(2):445-453.

[26] Schoof PH. Stentless Valve Dehiscence. Journal of Thoracic Cardiovascular Surgery 2008;136(1):231.

[27] Al Kindi AH, Huu AL, Shum-Tim D. Early Stenosis of Stentless Aortic Valve Prosthesis: A Word of Caution. Annals of Thoracic Surgery 2012;

[28] Tuncer A,Tuncer EY,Polat A, Mataracı İ, Keleş C, Aulasaleh S, Boyacıŏlu K, Kara İ, Kirali K. Axillary Artery Cannulation in Ascending Aortic Pathologies. Turkish Journal of Thoracic Cardiovascular Surgery 2011;19(4):539-544.

[29] Güler M, Akıncı E, Dağlar B, Kırali K, Eren E, Balkanay M, Berki T, Gürbüz A, Yakut C. Continuous Retrograde Coronary Sinus Isothermic Blood Cardioplegia with no Antegrade Combination in Aortic Valve Surgery. Turkish Journal of Thoracic Cardiovascular Surgery 1998;6(3):292-300.

[30] Kırali K, Göksedef D, Yakut C. Reverse "U" Aortotomy for Aortic Valve Replacement After Previous Coronary Artery Bypass Grafting. Journal of Cardiac Surgery 2005;20(3):269-270.

[31] Kobayashi J. Stentless Aortic Valve Replacement: An Update. Vascular Healt Risk Management 2011;7:345-351.

[32] Beholz S, Dushe S, Konertz W. Continuous Suture Technique for Freedom Stentless Valve: Reduced Crossclamp Time. Asian Cardiovascular Thoracic Annals 2006;14(2): 128-133. 
[33] Song Z, lehr EJ, Wang S. An Alternative Subcoronary Implantation Technique Decreases the Risk of Complete Heart Block After Stentless Aortic Valve Replacement. Journal of Cardiovascular Disease Research 2012;3(1):46-51.

[34] Aymard T, Eckstein F, Englberger L, Stalder M, Kadner A, Carrel T. TheSorinFreedomSOLOStentlessAorticValve:TechniqueofImplantationandOperativeResultsin109Patients.Journal of Thoracic Cardiovascular Surgery 2010;139(3):775-777.

[35] Repossini A, Kotelnikov I, Bouchikhi R, Torre T, Passaretti B, Parodi O, Arena V. Single-suture Line Placement of a Pericardial Stentless Valve. JournalofThoracicCardiovascularSurgery 2005;130(5):1265-1269.

[36] Pillai R, Ratnatunga C, Soon JL, Kattach H, Khalil A, Jin XY. 3f Prosthesis Aortic Cusp Replacement: Implantation Technique and Early Results. Asian Cardiovascular Thoracic Annals 2010;18(1):13-16.

[37] D'OnofrioA, MessinaA, LorussoR, AlfieriOR, FusariM, RubinoP, RinaldiM, DiBartolomeoR, GlauberM, TroiseG, GerosaG. Sutureless Aortic Valve Replacement as an Alternative Treatment for Patients Belonging to the "Gray Zone" Between Transcatheter Aortic Valvelimplantation and Conventional Surgery: A Propensity-matched, Multicenter Analysis. JournalofThoracicCardiovascularSurgery 2012 Sep 10. pii: S0022-5223(12)00883-5. doi: 10.1016/j.jtcvs.2012.07.040. [Epub ahead of print]

[38] Shrestha M, KhaladjN, BaraC, HoefflerK, HaglC, HaverichA. A Ataged Approach Towards Interventional Aortic Valve Implantation with a Sutureless Valve: Initial Human Implants. ThoracicCardiovascularSurgeon 2008;56(7):398-400.

[39] Santarpino G, Pfeiffer S, Concistrè G, Fischlein T. ASupra-annularMalpositionofthePercevalSSuturelessAorticValve:The' $\chi$-movement'RemovalTechniqueandSubsequentReimplantation.Interactive Cardiovascular Thoracic Surgery 2012;15(2):280-281.

[40] Folliguet TA, Laborde F, Zannis K, Ghorayeb G, haverich A, Shrestha M. Sutureless Percaval Aortic Valve Replacement: Results of Two European Centers. Annals of Thoracic Surgery 2012;93(5):1483-1488.

[41] Santarpino G, Pfeiffer S, Schmidt J, Concistrè G, Fischlein T. SuturelessAorticValveReplacement:First-yearSingle-centerExperience.Annals of Thoracic Surgery2012;94(2): 504-508.

[42] Cox JL, Ad N, Myers K, Gharib M, Quijano RC. Tubular Heart Valves: A New Tissue Prosthesis Design - Preclinical evaluation of the 3f Aortic Bioprosthesis. Journal of Thoracic Cardiovascular Surgery 2005;130(2):520-527.

[43] Risteski P, Adami C, Papadopoulos N, Sirat SA, Moritz A, Doss M. Leaflet Replacement for Aortic Stenosis Using the 3f Stentless Aortic Bioprosthesis: Midterm Results. Annals of Thoracic Surgery 2012;93(4):1134-1140. 
[44] Martens S, Sadowski J, Eckstein FS, Bartus K, Kapelak B, Sievers HH, Schlensak C, Carrel T. ClinicalExperiencewiththeATS3fEnable®SuturelessBioprosthesis.European Journal of Cardiothoracic Surgery 2011;40(3):749-755.

[45] Sepehripour AH, Harling L, Athanasiou T. What Are the Current Results of Sutureless Valves In High-risk Aortic Valve Disease Patients? Interactive Cardiovascular Thoracic Surgery 2012;14(5):615-621.

[46] HolmesDRJr, MackMJ, KaulS, AgnihotriA, AlexanderKP, BaileySR, CalhoonJH, CarabelloBA, DesaiMY, EdwardsFH, FrancisGS, GardnerTJ, KappeteinAP, LinderbaumJA, MukherjeeC, MukherjeeD, OttoCM, RuizCE, SaccoRL, SmithD, ThomasJD. 2012 ACCF/AATS/SCAI/STS Expert Consensus Document on Transcatheter Aortic Valve Replacement: Developed in Collaboration with the American Heart Association, American Society of Echocardiography, European Association for Cardio-Thoracic Surgery, Heart Failure Society of America, Mended Hearts, Society of Cardiovascular Anesthesiologists, Society of Cardiovascular Computed Tomography, and Society for Cardiovascular Magnetic Resonance. AnnalsofThoracicSurgery 2012;93(4): 1340-1395.

[47] Kirali K, Mansuroğlu D, Omeroğlu SN, Erentuğ V, Mataraci I, Ipek G, Akıncı E, Işık Ö, Yakut C. Five-year Experience in Aortic Root Replacement with the Flanged Composite Graft. Annals of Thoracic Surgery 2002;73(4):1130-1137.

[48] Kirsh MEW, Ooka T, Zannis K, deux JF, Loisance DY. Bioprosthetic Replacement of The Ascending Thoracic Aorta: What Are The Options? European Journal of Cardiothoracic Surgery 2009;35(1):77-82.

[49] Urbansky PP, Hacker RW. Replacement of the Aortic Valve and Ascending Aorta with a Valved Stentless Composite Graft: Technical Considerations and Early Clinical Results. Annals of Thoracic Surgery 2000;70(1):17-20.

[50] De Paulis R, Nardi P, De Matteis GM, Polisca P, Chiariello L. Bentall Procedure with a Stentless Valve and a New Aortic Root prosthesis. Annals of Thoracic Surgery 2001;71(4):1375-1376.

[51] Kırali K, Sarıkaya S, Elibol A, Göçer S, Özer T, Altaş Ö, Ünal ÜS, Şişmanoğlu M. Aortic Root Replacement with the Reimplantation Procedure: Simplifiying the Sizing of Tubular Graft. 20th Annual Meeting for Asian Society for Cardiovascular and Thoracic Surgery, 7-11 March 2012; Bali, Indonesia.

[52] Kaya A, Heijmen RH, Kelder JC, Morshuis WJ. First 102 Patients With the Biovalsalva Conduit for Aortic Root Replacement. Annals of Thoracic Surgery 2012;94(1): 72-77.

[53] Hemmer WB, Botha CA, Böhm JO, Herrmann T, Starck C, Rein JG. replacement of the Aortic Valve and Ascending Aorta with an Extended Root Stentless Xenograft. Annals of Thoracic Surgery 2004;78(6):2150-2153. 
[54] Massetti M, Veron S, Neri E, Coffin O, le Page O, Babatasi G, Buklas D, Maiza D, Gerard JL, Khayat A. Long-term Durability of Resection and End-To-End Anastomosis for Ascending Aortic Aneurysms. Journal of Thoracic Cardiovascular Surgery 2003;127(5):1381-1387.

[55] Akpınar B, Güden M, Aytekin S, Sanisoğlu I, Sagbas E, Ozbek U, Caynak B, Bayramoglu Z. The Use of Stentless Valves for Root Replacement During Repair of Ascending Aortic Aneurysms with Aortic Valve Regurgitation. Heart Surgery Forum 2002;5(1):52-56.

[56] Carrel TP, Berdat P, Englberger L, Eckstein F, Immer F, Seiler C, Kipfer B, Schmidt J. Aortic Root Replacement with a New Stentless Aortic Valve Xenograft Conduit: Preliminary Hemodynamic and Clinical Results. Journal of Heart Valve Disease 2003;12(6):752-757.

[57] Rabus MB, Kirali K, KayalarN, MataraciI, YanartasM, Ulusoy-BozbugaN, YakutC. Effects of Patient-Prosthesis Mismatch on Postoperative Early Mortality in Isolated Aortic Stenosis. Journal of Heart Valve Disease2009;18(1):18-27.

[58] Head SJ, Mokhles MM, Osnabrugge RLJ, Pibarot P, Mack MJ, Takkenberg JJM, Bogers JJCA, Kappetein AP. The Impact of Prosthesis-Patient Mismatch on Long-term Survival After Aortic Valve Replacement: A Systematic Review and Meta-Analysis of 34 Observational Studies Comprising 27186 Patients with 133141 Patient-years. European Heart Journal 2012;33():1518-1529.

[59] Shiono N, Watanabe Y, Kawasaki M, Yokomuro H, Fujii T, Koyama N. Evaluation of Bioprosthetic Valve for Small Aortic Root in Elderly Patients. Asian Cardiovascular Thoracic Annals 2007;15(1):102-105.

[60] Ardal H, Toker ME, Rabuş MB, Uyar İ, Antal A, Şişmanoğlu M, Mansuroğlu D, Kırali K, Yakut C. Does Aortic Root Enlargement Impair theOoutcome of Patients With Small Aortic Root? Journal of Cardiac Surgery 2006;21(5):449-453.

[61] Bical OM, Nutu O, D2eleuze P. A Technique of Aortic Annulus Enlargement with a Freestyle Stentless Bioprosthesis. Annals of Thoracic Surgery 2012;93(3):680-681.

[62] Goland S, Trento A, Czer LSC, Eshaghian S, Tolstrup K, Naqvi TZ, De Robertis MA, Mirocha J, Iida K, Siegel RJ. Thoracic Aortic Arteriosclerosis in Patients With Degenerative Aortic Stenosis With and Without Coexisting Coronary Artery Disease. Annals of Thoracic Surgery 2008;85(1):113-119.

[63] GillinovAM, LytleBW, HoangV, CosgroveDM, BanburyMK, McCarthyPM, SabikJF, PetterssonGB, SmediraNG, BlackstoneEH. The Atherosclerotic Aorta at Aortic Valve Replacement: Surgical Strategies and Results. Journal of Thoracic Cardiovascular Surgery 2000;120(5):957-963.

[64] Rode's-Cabau J,Webb JG, Cheung A, Ye J, Dumont E, Feindel CM, Osten M, Natarajan MK, Velianou JL, Martucci G, DeVarennes B, Chisholm R, Peterson MD, Lichtenstein SV, Nietlispach F, Doyle D, DeLarochellie're R, Teoh K, Chu V, Dancea A, 
Lachapelle K, Cheema A, Latter D, Horlick E. Transcatheter Aortic Valve Implantation for theTtreatment of Severe Symptomatic Aortic Stenosis in Patients at Very High or Prohibitive Surgical Risk: Acute and Late Outcomes of the Multicenter Canadian Experience. Journal of American Collage Cardiology 2010;55(11):1080-1090.

[65] Buz S, Pasic M, Unbehaun A, Drews T, Dreysse S, kukucka M, Mladenow A, Hetzer R. Trans-apical Aortic Valve Implantation in Patients with Severe Calcification of the Ascending Aorta. European Journal of Cardiothoracic Surgery 2011;40(2):463-468.

[66] RabuşMB, KayalarN, SareyyüpoğluB, ErkinA, Kirali K, YakutC. Hypercholesterolemia Association with Aortic Stenosis of Various Etiologies. JournalofCardiacSurgery 2009;24(2):146-150.

[67] Taş S, Dönmez AA, Kırali K, Alp M, Yakut C. Aortic Valve Replacement for a Patient with Glucose-6-Phosphate Dehydrogenase Deficiency and Autoimmune Hemolytic Anemia. Jornal of Cardiac Surgery 2005;20(4):380-381.

[68] Kirali K, Aksoy E, Buyukbayrak F, Yanartas M, Elibol A, Ozer T, Boyacioglu K, Kis M, Sismanoglu M, Mataraci I. Does Thrombocytopenia Aggravate early Outcome After Aortic Valve Replacement with a Bioprosthesis. $16^{\text {th }}$ World Congress on Heart Disease for Intenational Academy of Cardiology, 23-26 July 2011; Vancouver, Canada.

[69] RepossiniA, BlochD, MunerettoC, PiccoliP, BisleriG, BeholzS. Platelet Reduction After Stentless Pericardial Aortic Valve Replacement. InteractiveCardiovascularThoracicSurgery 2012;14(4):434-438.

[70] GersakB, GartnerU, AntonicM. ThrombocytopeniaFollowingImplantationoftheSstentlessBiologicalSorinFreedomSOLOValve.Journal of Heart Valve Disease 2011;20(4): 401-406.

[71] El-Hamamsy I, Zaki M, Stevens LM, ClarkLA, RubensM, MelinaG, YacoubMH. Rate of Progression and Functional Significance of Aortic Root Calcification After homograft versus Freestyle AorticRrootRreplacement. Circulation 2009;120(Suppl 1):S269S275.

[72] Erdoğan HB, Kayalar N, Ardal H, Ömeroğlu SN, Kırali K, Güler M, Akıncı E, Yakut C. Risk Factors for Requirement of Permanent Pacemaker Implantation After Aortic Valve Replacement. Journal of Cardiac Surgery2006;21(3):211-215.

[73] Kincaid EH, Cordell R, Hammon JW, Adair SM, Kon ND. Coronary Insufficiency After Stentless Aortic Root Replacement: Risk Factors and Solutions. Annals of Thoracic Surgery 2007;83(3):964-968.

[74] Schoof P, Baur L, Kappetein A, Hazekamp M, vanRijk-Zwikker G, Huysmans H. Dehiscence of the Freestyle Stentless Bioprosthesis. Seminars in Thoracic Cardiovascular Surgery 1999;11(suppl 1):133-138.

[75] Hopkins R, Gitter H, Stave J, Bert A, Atalay M. Stable Partial Dehiscence of Aortic Homograft Inserted Freehand by Using the Subcoronary Intra-aortic Root Noncoro- 
nary Sinus Ross Scallop Inclusion technique. Journal of Thoracic Cardiovascular Surgery 2008;135(1):214-216.

[76] David TE, Ivanov J, eriksson MJ, Feindel CM, Rakowski H. Dilatation of the Sinotubular Junction Causes Aortic Insufficiency After Aortic Valve Replacement with the Toronto SPV Bioprosthesis. Journal Thoracic Cardiovascular Surgery 2001;122(5): 929-934.

[77] WeltertL, NardellaS, GirolaF, ScaffaR, BellisarioA, MaselliD, DePaulisR. Diastolic Properties of the SorinSolo, ATS 3F, Edwards Prima Plus and Medtronic Freestyle Stentless Valves: An Independent in-vitro Comparison. JournalHeartValveDis-ease. 2012;21(1):99-105.

[78] Nötzold A, Scharfschwerdt M, Thiede L, Hüppe M, Sievers HH. In-vitro Study on the Relationship Between Progressive Sinotubular Junction Dilatation and Aortic Regurgitation for Several Stentless Aortic Valve Substitutes. European Journal of Cardiothoracic Surgery 2005;27(1):90-93.

[79] Scharfschwerdt M, Sievers HH, Hussein A, Kraatz EG, Misfeld M. Impact of Progressive Sinotubular Junction Dilatation on Valve Competence of the 3F Aortic and Sorin Solo Stentless Bioprosthetic Heart Valves. European Journal of Cardiothoracic Surgery 2010;37(3):631-634.

[80] Borger MA, Prasongsukarn K, Armstrong S, Feindel CM, David TE. Stentless Aortic Valve Reoperations: A Surgical Challenge. Annals of Thoracic Surgery 2007;84(3): 737-744.

[81] Finch J, Roussin I, Pepper J. Failing Stentless Aortic Valves: Redo Aortic Root Replacement or Valve in a Valve. European Journal of Cardiothoracic Surgery 2012;42():

[82] Ferrari E. Transapical Aortic 'valve-in-valve' Procedure for Degenerated Stented Bioprosthesis. European Journal of Cardiothoracic Surgery 2012;41(3):485-490.

[83] Mihaljevic T, Nowicki ER, Rajeswaran J, Blackstone EH, Lagazzi L, Thomas J, Lytle BW, Cosgrove DM. Survival After Valve Replacement For Aortic Stenosis: Implications for Decision Making. Journal of Thoracic Cardiovascular Surgery 2008;135(6): 1270-1279.

[84] Luciani GB, Casali G, Auriemma S, SantiniF, MazzuccoA. Survival After Stentless and Stented Xenograft Aortic Valve Replacement: A Concurrent, Controlled Trial. Annals of Thoracic Surgery 2002;7485):1443-1449.

[85] Dunning J, Graham RJ, Thambyrajah J, StewartMJ, KendallSW, HunterS. Stentless vs Stented Aortic Valve Bioprostheses: A Prospective Randomized Controlled Trial. European Heart Journal 2007;28(19):2369-2374.

[86] Murtaza B, Pepper JR, Jones C, Nihoyannopoulos P, Darzi A, Athanasiou T. Does Stentless Aortic Valve Implantation Increase perioperative Risk? A Critical Appraisal 
of the Literature and Risk of Bias Analysis. European Journal of Cardiothoracic Surgery 2011;39(5):643-652.

[87] Westaby S, JönsonA, PayneN, SaitoS, JinXY, DelRizzoDF, GrunkemeierG. Does The Use of a Stentless Bioprosthesis Increase Surgical Risk?SeminarsThoracicCardiovascularSurgery 2001;13(4, Suppl 1):143-147.

[88] Borger MA, Carson SM, Ivanov J, RaoV, ScullyHE, FeindelCM, DavidTE. Stentless Aortic Valve Are Hemodynamically Superior to Stented valves during Mid-term follow-up: A Large Retrospective Study. Annals of Thoracic Surgery 2005;80(6): 2180-2185.

[89] Lehmann S, Walther T, Kempfert J, Leontjev A, Ardawan R, Falk V, Mohr FW. Stentless Versus Conventional Xenograft Aortic Valve Replacement: Midterm Results of a Prospectively Randomized Trial. Annals of Thoracic Surgery 2007;84(2):467-472.

[90] Bach DS, Kon ND, Dumesnil JG, Sintek CF, Ross DB. Ten-Year Outcome after Aortic Valve Replacement with the Freestyle Stentless Bioprosthesis. Annals of Thoracic Surgery 2005;80(2):480-487.

[91] Mohammadi S, Tchana-Sato V, Kalavrouziotis D, Voisine P, Doyle D, Baillot R, Sponga S, Metras J, Perron J, Dagenais F. Long-termClinicalandEchocardiographicFollowupoftheFreestyleStentlessAorticBioprosthesis.Circulation 2012;126(11 Suppl 1):S198S204.

[92] Bach DS, Kon ND, DumesnilJG, SintekCF, DotyDB. Ten-year Outcome After Aortic Valve Replacement With the Freestyle Stentless Bioprosthesis. AnnalsofThoracicSurgery 2005;80(2):480-486.

[93] Borger MA, Prasongsukarn K, Armstrong S, Feindel CM, David TE. Stentless Aortic Valve Reoperations: A Surgical Challenge. Annals of Thoracic Surgery 2007;84(3): 737-744.

[94] Jeong DS, Kim K-H, Ahn H. Long-term Results of the Leaflet Extension Technique in Aortic Regurgitation: Thirteen Years of Experience in a Single Centre. Annals of Thoracic Surgery 2009;88(1):83-89.

[95] Cohen G, Zagorski B, Christakis GT, Joyner CD, Vincent J, Sever J, HarbiS, FederElituvR, MoussaF, GoldmanBS, FremesSE. Are Stentless Valves Hemodynamically Superior to Stented valves? Long-term Follow-up of a randomized trial Comparing Carpentier-Edwards Pericardial Valve With The Toronto Stentless porcine Valves? Journal of Thoracic Cardiovascular Surgery 2010;139(4):848-859.

[96] Chamber JB, Rimington HM, Hodson F, Rajani R, Blauth CI. The Subcoronary Toronto Stentless Versus Supra-annular Perimount Stented Replacement Aortic Valve: Early Clinical and Hemodynamic results of a Randomized Comparison in 160 Patients. Journal of Thoracic Cardiovascular Surgery 2006;131(4):878-882.

[97] Iliopoulos DC, Deveja AR, Androutsopoulou V, Filias V, Kastelanos E, Satratzemis V, Khalpey Z, Koudoumas D. Single-centerExperienceUsingtheFreedomSOLOAor- 
ticBioprosthesis. Journal of Thoracic Cardiovascular Surgery 2012;(:http://dx.doi.org/ 10.1016/j.jtcvs.2012.06.041)

[98] BeholzS, RepossiniA, LiviU, SchepensM, ElGabryM, MatschkeK, TrivediU, EckelL, DapuntO, ZamoranoJL. The Freedom SOLO Valve for Aortic Valve Replacement: Clinical and Hemodynamic Results from a Prospective Multicenter Trial. JournalHeartValveDisease 2010;19(1):115-123.

[99] Linneweber J, Heinbokel T, Christ T, Claus B, Kossagk C, Konertz W. Clinical Experience with the ATS 3F Stentless Aortic Bioprosthesis: Five Years' Follow Up. Journal Heart Valve Disease 2010;19(6):772-777.

[100] TanakaK, KinoshitaT, FujinagaK, KanemitsuS, TanakaJ, SuzukiH, TokuiT. HemodynamicPerformanceoftheEdwardsPrimaPlusStentlessValveat1Year. GeneralThoracicCardiovascularSurgery2008;56(9):441-445.

[101] Luciani GB, Viscardi F, Cresce GD, Faggian G, Mazzucco A.Seven-Year Performance of the Edwards Prima Plus Stentless Valve with the Intact Non-Coronary Sinus Technique.Journal of Cardiac Surgery 2008;23(3):221-226.

[102] Kappetein AP, Braun J, Baur LHB, Prat A, Peels K, Hazekamp MG, Schoof PH, Huysmans HA. Outcome and Follow-up of Aortic Valve Replacement with The Freestyle Stentless Bioprosthesis. Annals of Thoracic Surgery 2001;71(2):601-607.

[103] Van Nooten G, Caes F, Francois K, Van BY, Taeymans Y. Stentless or Stented Aortic Valve Implants in Elderly Patients? European Journal of Cardiothoracic Surgery 1999;15(1):31-36.

[104] Eriksson MJ, Rosfors S, Radegran K, Brodin LA. Effects of Exercise on Doppler-derived Pressure Difference, Valve Resistance, and Effective Orifice Area in Different Aortic Valve Prostheses of Similar Size. American Journal of Cardiology 1999;83(4): 619-622.

[105] Bleiziffer S, Eichinger WB, Wagner I, Guenzinger R, Bauernschmitt R, Lange R. The Toronto Root Stentless Valve in the Subcoronary Position is Hemodynamically Superior to the Mosaic Stented Completely Supra-annular Bioprosthesis. Journal of Heart Valve Disease 2005;14(6):814-821.

[106] Fries R, Wendler O, Schieffer H, Schaefers HJ. Comparative Rest and Exercise Hemodynamics of 23-mm Stentless Versus 23-mm Stented Aortic Bioprostheses. Annals of Thoracic Surgery 2000;69(3):817-822. 
